\title{
Redefining clinical outcomes and endpoints in glaucoma
}

\author{
Timothy E. Yap, ${ }^{1,2}$ Eduardo M. Normando, ${ }^{1,2}$ Maria Francesca Cordeiro 1,2,3 \\ 1 The Western Eye Hospital, Imperial College Healthcare NHS Trust (ICHNT), London NW1 5QH, UK \\ 2 The Imperial College Ophthalmic Research Group (ICORG), Imperial College London NW1 5QH, UK \\ 3 Glaucoma and Retinal Neurodegeneration Group, Department of Visual Neuroscience, UCL Institute of Ophthalmology, London \\ EC1V 9EL, UK \\ Correspondence to: Prof M. F. Cordeiro, UCL Institute of Ophthalmology 11-43 Bath Street, London EC1V 9EL UK E-mail: \\ M.Cordeiro@ucl.ac.uk
}

\section{Summary}

Introduction: Increasing life expectancy and ageing populations across the world are causing the number of glaucoma patients to rise dramatically. With longer lifespans also comes the need to improve the timeframe and accuracy with which we can diagnose, monitor and treat patients, ensuring longevity of vision contributes to a meaningful quality of life. Current markers used in glaucoma practice are in many cases suboptimal in their ability to accurately identify glaucomatous damage in time to prevent irreversible optic neuropathy. Areas covered: This review summarises the important properties of successful biomarkers and surrogates, and relates this to how intraocular pressure, visual field testing, and imaging have been refined to improve early diagnosis and progression analysis of glaucoma patients. Secondly, we discuss newer concepts in imaging, genetics, and objective measures which may provide biomarkers and surrogate endpoints with which to develop novel treatments in the future. Expert Commentary: We summarise the key relevant points in glaucoma research, and the current techniques being trialled that are most likely to lead to valuable biomarkers for the future.

\section{Keywords}

Glaucoma; biomarkers; endpoints; surrogate marker; neurodegeneration. 


\section{Introduction}

\subsection{Tackling the burden of disease}

Glaucoma is one of the leading worldwide causes of irreversible blindness [72]. It was estimated that in 2010 there were 60.5 million sufferers worldwide, with this figure projected to rise to 111.8 million by 2040 [216]. However, the Ocular Hypertension Treatment Study (OHTS) demonstrated that only $9.5 \%$ of those with untreated ocular hypertension develop glaucoma [114]. Considering this, we must aim to develop diagnostic tools with high specificity to identify patients who will not progress to glaucoma in their lifetime. Conversely, it is crucial we develop new tests with high sensitivity in order to manage and monitor treatment early, for those at risk of blindness. Finding new ways to detect ocular neurodegeneration will also help to uncover the underlying pathological processes and identify novel treatments.

The need to improve glaucoma diagnosis and monitoring is especially pertinent in the developing world where the number of eye-care professionals is struggling to match the targets set by Vision 2020 [168]. Moreover, these patients are often at higher risk of glaucoma and more likely to develop severe disease and blindness [125], whilst potentially vulnerable to widening health inequalities if not able to access new technologies. Hence, novel techniques must simplify the acquisition process, avoiding reliance on operator skills or patient ability in order to achieve the most reliable, universally accessible and transferrable data. New ways of monitoring stable and low risk glaucoma patients such as virtual clinics have been developed to meet the capacity of national healthcare systems [48]. 
This review aims to highlight the characteristics of valuable surrogate markers and endpoints, and discuss how those currently used in research and clinical practice have been improved and extended. Secondly, we will explore exciting novel endpoints and biomarkers that have potential to change the way we monitor glaucomatous degeneration, testing new treatments and hopefully identify early disease.

1.2 Defining terminology: biomarkers, clinical endpoints and surrogate endpoints

A biomarker is shortened form for a biological marker, with the most widely quoted definition by the National Institutes of Health Biomarkers Definitions Working Group [28] as:

"A characteristic that is objectively measured and evaluated as an indicator of normal biological processes, pathogenic processes, or pharmacologic responses to a therapeutic intervention"

A clinical outcome or clinical endpoint is seen from the patient's point of view, and defined as [55]:

"A characteristic or variable that reflects how a patient feels, functions, or survives"

A surrogate marker is used as a predictor of a clinical outcome. These are often regarded as more readily accessible and faster measures of treatment response or disease activity [171]. In addition to correlating with, and predicting the clinical outcome, a surrogate marker must comprehensively 'capture' the effect of treatment on the clinically relevant endpoint. Prentice 
suggested four criteria for surrogate markers; (1) the surrogate endpoint has a significant impact on the true end point, (2) treatment has a significant impact on the surrogate endpoint, (3) treatment has a significant impact on the true endpoint, (4) the full effect of treatment on the true endpoint can be captured by the surrogate [176]. However, these have not been without controversy. Berger discusses the complexities of assumptions using surrogate markers, pointing out that if a surrogate endpoint is validated using one treatment, how is it possible to progress to using this endpoint to trial a different treatment as one would have to already know that the new treatment has a significant impact on the true endpoint to satisfy the criteria [27]. This also serves as a reminder of the risks and benefits to be weighed up before using a surrogate marker, to avoid harm [73].

\subsection{Using biomarkers and clinical outcomes in glaucoma research and clinical practice}

In chronic conditions such as glaucoma where patients can progress slowly and are followed up over long periods of time, it is important to obtain reliable indices to benchmark progression and gauge effectiveness of treatments on outcomes that are clinically relevant. Ideally, we would be able to take into account visual disability when making treatment decisions, however quantification of such a qualitative parameter is challenging.

In glaucoma, the 'gold standard' test for estimating a patient's visual impairment from field loss is standard automated perimetry (SAP). However, visual field defects can take many years to develop, during which the process of irreversible Retinal Ganglion Cells (RGCs) damage occurs [150]. For this reason, surrogate endpoints are under investigation aiming to reduce the cost and duration of clinical trials and expedite the release of new treatments [235]. A surrogate endpoint that is used in both clinical and trial settings can provide prognostic information and evidence-based treatment decisions. Aside from Prentice's criteria, more practical properties 
of a good marker include ease with which it can be recorded, interpreted, and its costeffectiveness. As we recognise glaucoma as a heterogeneous group of conditions with multifactorial pathogeneses, we will need to be specific about which biomarker is most appropriate to fully capture the characteristics relevant to each patient's individual disease pathology [139].

\section{Current markers and endpoints}

\subsection{Intraocular pressure}

Intraocular pressure (IOP) is the only modifiable risk factor in preventing the onset and progression of glaucoma. The 'gold-standard' technique for estimating IOP is Goldmann applanation tonometry quoted as having reasonable repeatability ( $\mathrm{R} 95=2.0 \mathrm{mmHg}, \mathrm{CV} 4.9 \%$ ) and reproducibility $(95 \%$ limits of agreement $=-2.0$ to $3.4 \pm 2.7 \mathrm{mmHg})$ under test conditions [209]. Whether it is the peaks or fluctuations in intraocular pressure that is most harmful, getting an accurate assessment of either measure from sporadic clinic visits is challenging [15]. Furthermore, different factors can affect readings including corneal thickness [200], IOP diurnal variation $[15,52,79,198]$, widening or narrowing of the palpebral fissure [103, 156], the Mueller or Valsalva manoeuvres $[140,187,227]$, recent exercise $[130,148,186]$, and positioning [213]. Diurnal variation alone has been shown to be up to $6.4 \pm 1.4 \mathrm{mmHg}$ in healthy subjects and $10.3 \pm 2.0 \mathrm{mmHg}$ in glaucomatous subjects. The majority of peak values occur in the morning around 7-9am before patients are typically seen in clinic [198]. IOP "phasing" throughout the day, is used to evaluate IOP fluctuation, however this is time consuming and possibly lacks reproducibility in itself [205].

The OHTS has demonstrated that lowering IOP reduces the rate of conversion to glaucoma in ocular hypertensive patients $(\mathrm{NNT}$ (number needed to treat) $=20)[90,100,114]$. Given the 
rapid response to treatment, and the fact that it is the target of all currently available therapies, IOP has been the biomarker of choice in glaucoma trials. However, it has been shown $4.4 \%$ of patients with adequately treated IOP will still progress to glaucoma [114]. This indicates that IOP is an imperfect surrogate marker for glaucoma progression. The Collaborative NormalTension Glaucoma Study (CNTGS) has shown that reducing IOP also prevents disease progression in 'normal-tension' glaucoma (NTG) [63, 220]. One study by Krupin et al. questions whether this is a purely pressure-dependent effect as they found a significantly lower rate of visual field progression with brimonidine (9.1\%) when compared to timolol $(39.2 \%$, $\mathrm{P}=.001)$ despite comparable IOPs [122], suggesting a potential neuroprotective effect of brimonidine, with some provisos [46].

The use of IOP fluctuation as an independent risk factor and possible biomarker in glaucoma has been debated, with varying results $[15,25,152]$. To further characterise IOP variation and the biomechanical properties of the eye, several continuous IOP monitoring systems have been devised [60]. Over a few seconds, dynamic contour tonometry (DCT) has been used to show IOP fluctuations within the cardiac cycle (ocular pulse amplitude, OPA) [174, 178]. IOP monitoring over longer periods has been achieved with a contact-lens based system [146], or implantable devices inserted into the ciliary sulcus or orbital wall $[61,121]$. This latter system was explored in non-human primate glaucoma models and concluded that IOP variation did not predict any change in retinal nerve fibre layer thickness [77]. However, it did highlight how changes in body positioning significantly influenced IOP, with supine and lateral decubitus (dependent eye) positioning causing a rise in IOP [224].

\subsection{Structural biomarkers}

Understanding the structure-function relationship between the optic nerve head $(\mathrm{ONH})$, retinal nerve fibre layer (RNFL) and visual field defects is crucial to being able to identify biomarkers 
that predict which patients will go on to develop visual loss. Often, progressive RNFL thinning and loss of neuroretinal rim (NRR) with characteristic cupping of the disc occurs prior to the development of visual field defects [3, 252]. In 'pre-perimetric glaucoma' patients[183], this lead-time has been estimated to be around 2 years on average, stretching to as long as 8 years in up to $19 \%$ of cases $[123,249]$. It is during this gap that detection of structural changes ideally should be made in order to initiate treatment before functional damage occurs. However, in patients with advanced disease, a 'floor effect' of neuroretinal rim thickness has been reported. This is suspected to consist of glial cells and blood vessels beyond which accurate segmentation of layers on OCT images cannot occur [29, 181], indicating the need for alternative biomarkers to monitor these patients.

In order to image the earliest structural changes, the exact site of cellular injury to the RGC needs to be considered. Most recent experimental evidence supports axonal injury as the culprit leading to retrograde cell death $[10,184]$. It has been proposed that damage to the RGCs may occur at the level of the lamina cribrosa by impedance of axonal transport flow as the trigger for eventual apoptosis at the cell body [62]. Considering the increasing sensitivity and specificity of retinal imaging devices, the National Eye Institute (NEI) and Food and Drug Administration (FDA) Center for Drug Evaluation and Research have recommended that the use of structural biomarkers as a surrogate for visual outcomes in glaucoma could be used, as long as they can be proven to predict clinically relevant functional change [235].

Ophthalmoscopic estimation of cup-disc-ratio is unreliably subjective [112, 214] and has been superseded by advances in imaging technology. Structural characteristics of the optic nerve can be objectified using imaging modalities such as stereoscopic photography [18], confocal scanning laser ophthalmoscopy (cSLO) [39], scanning laser polarimetry (SLP) [236], and optical coherence tomography (OCT) [196]. Of these, the most widely used in current clinical practice is OCT, which has been quoted as having a sensitivity and specificity of $83 \%$ and $88 \%$ 
respectively for detecting significant RNFL abnormalities [35], in addition to good repeatability [58] [212]. Furthermore, images are quick to acquire and the acquisition process is well tolerated by patients, with optical media opacities being the major limiting factor for this technology $[99,127]$.

Current spectral-domain OCT (SD-OCT) scanning protocols in glaucoma aim to assess either the optic disc where RNFL thickness, minimum rim width, neuroretinal rim (NRR) area and cup volume can be measured, and the macula region where the thickness of the ganglion cell complex (GCC) can be mapped out. Baseline structural parameters as predictors of progression have been investigated to assess the implications of imaging on initial consultation. RNFL thickness (Area Under Receiver Operating Characteristic curve $=0.839,95 \%$ CI $0.757-0.921$ ) and Bruch's membrane opening-minimum rim width (BMO-MRW) (AUROC curve $=0.821$, 95\% CI $0.731-0.921$ ) [81] have good ability to distinguish pre-perimetric patients from healthy controls at baseline. GCC focal loss volume (AUROC curve $=0.753,95 \%$ CI 0.683 0.814 ), and nerve fibre layer (NFL) focal loss volume (AUROC curve $=0.655,95 \%$ CI 0.583 - 0.728) [255] were also found predictive of future progression amongst glaucoma suspects and pre-perimetric glaucoma patients to varying degrees. Incorporating baseline structural parameters into composite markers with corneal thickness, age and visual field indices has been shown to marginally improve accuracy in certain studies [254, 255].

Progression analysis of structural markers as a potential surrogate marker might be a more useful concept. When imaging the same patient longitudinally, all the variables present in the instruments' normative database are mitigated [191]. Longitudinal studies [40, 135, 149, 153, 154], have shown the predictive value of structural progression having hazard ratios quoted up to 8.44 (95\% CI 3.30-21.61) when using trend-based progression analysis of serial RNFL thickness maps [249]. As to whether structural parameters measured by OCT are a true 
surrogate marker for visual field progression is yet to be fully answered. Using cSLO, a previously widespread method for detecting structural progression in glaucoma, NRR area measurements were shown to satisfy Prentice's criteria for surrogacy, with $65 \%$ of IOPlowering treatment effect 'captured' by this marker [151], possibly indicating similar potential for other imaging modalities.

Swept-source OCT (SS-OCT) technology uses a longer wavelength $(1050 \mathrm{~nm})$ than spectral domain OCT (SD-OCT) $(840 \mathrm{~nm})$ enabling it to image more of the deeper ocular structures such as the posterior lamina cribrosa surface and the choroid [145], whilst providing similar diagnostic accuracy to SD-OCT [247]. Greater tissue penetration could allow for further studies on the biomechanics of the lamina and its effect on axonal transport and cellular damage [62]. The features of the lamina associated with glaucoma include the depth of the anterior surface and insertion [74] [169] [128], shape [223], thickness [164], and focal defects [211, 248]. Lamina cribrosa depth has also been shown to be significantly different between hightension and normal-tension glaucoma subtypes [131] implicating intraocular pressure in these observations. With regards to monitoring progression and disease activity, the rate of change of posterior lamina displacement has been shown to predict the progression of visual field defects [245]. However, with both anterior and posterior depth displacement in glaucoma having been reported, this biomarker is yet to be fully characterised [246]. The significance of choroidal thickness (CT) measurements using SS-OCT in glaucoma is more controversial with the literature presenting conflicting results [204, 229, 253, 256].

OCT angiography is a new technology which uses the extreme speed of second generation SDand SS- OCT to evaluate retinal and choroidal microvasculature. In glaucoma, it has been used to assess the optic nerve and peripapillary regions $[94,106]$. Initial studies have shown significant reductions in peripapillary blood flow and vessel density [136, 231], which strongly 
correlated with RNFL thickness (Pearson R range: 0.652 to $0.771, \mathrm{P} \leq 0.0046$ ) [94]. Further studies have demonstrated a strong correlation between reduction in retinal blood flow in the temporal peripapillary zone and the presence of paracentral visual field defects in glaucoma patients [95]. Furthermore, a recent proof-of-concept study has shown the possibility of capturing treatment effect using this technique; in a young cohort of newly diagnosed glaucoma patients treated aggressively with IOP lowering medications, an increase in peripapillary capillary blood flow was inversely correlated with the IOP values [93]. Further work in a larger number of patients is needed to prove the significance of these initial findings in OCT angiography, as a potentially useful surrogate marker in investigating and treating the possible vascular component of glaucoma $[41,69,198]$.

Adaptive optics (AO) is a technology that can improve the real-time resolution of optical systems by using a deformable mirror to reduce optical aberrations [132]. Previously incorporated into fundus cameras and cSLO, AO in OCT combines the superior axial resolution of OCT with the ability of AO technology to improve lateral resolution, increasing threedimensional resolution of optic nerve head and retinal imaging to a theoretical $3 \mu \mathrm{m}^{3} /$ voxel [59]. In glaucoma this can enable visualisation of RNFL axon bundles [118], with initial studies demonstrating double the light reflectivity from these fibres when compared to surrounding tissue [117]. This brings the potential for a new biomarker to monitor progression in the specific cell type of interest in glaucoma, and with good reproducibility [117]. There is also some evidence to suggest reflectivity may reduce prior to RNFL thinning, allowing for earlier diagnosis [98]. As with SS-OCT, AO-OCT has been shown to image the lamina cribrosa including its posterior surface [202]. The addition of AO technology to SS-OCT in the future is likely to provide an excellent combination of depth penetration and resolution [107], and therefore further characterise the lamina changes in glaucoma that may become future 
surrogate markers.

\subsection{Visual Fields}

Visual field testing (perimetry) is currently the gold standard method to monitor visual loss in glaucoma. Automated Humphrey (Carl Zeiss Meditech, Dublin, CA) or Octopus (Haag-Streit) static visual field analysers are the most widely used as they are quick and less operatordependant than kinetic perimeters, with the latest threshold algorithms able to assess one eye in less than 4 minutes $[24,172]$. The number of points corresponding to the area of retina being tested depends on the schedule chosen, with 30-2, 24-2 and 10-2 settings indicating points 30 , 24, and 10 degrees from the central point of fixation respectively at which light sensitivity is measured. A reliable test requires a patient to fixate on a point and maintain concentration. Furthermore, an obvious learning effect has been documented, suggesting more than one and preferably at least three baseline visual fields should be used to assess glaucoma severity [76, 172]. For the significant number of patients with multiple comorbidities including those causing fatigue, musculoskeletal disease or dementia, it can be challenging to maintain the physical posture or the mental concentration to produce acceptable reliability indices such as low fixation losses, low false positives and low false negatives.

There are several factors that limit the performance of standard automated perimetry (SAP) in both clinical and research settings. During the lag time between onset of glaucomatous optic neuropathy and clinically detectable visual field defects ('pre-perimetric glaucoma') [165], it has been estimated that between $20-30 \%$ of RGCs are lost $[150,182]$. Progression is also typically slow in POAG with only $5.6 \%$ of patients reported to be progressing faster than $2.5 \mathrm{~dB}$ per year [89]. This could foreseeably affect the prompt initiation of treatment, or the choice of SAP as the primary outcome in clinical trials. One study has estimated that fourmonthly testing would be required to reliably identify a mean deviation (MD) change of $4 \mathrm{~dB}$ 
over the space of 2 years, a target that is difficult to meet in a public-funded clinical setting [36]. The first prospective placebo-controlled study to demonstrate the efficacy of a single drug using visual fields (24-2) was the United Kingdom Glaucoma Treatment Study (UKGTS). This showed latanoprost treatment in newly diagnosed POAG patients reduced the rate of visual field progression over a 24-month period [78]. The authors reported that their comparatively short duration was enabled by using altered event-based criteria from the Early Manifest Glaucoma Trial (EMGT), frequent visual field testing, and a large sample size $(n=516)$. Previously, large trials monitoring visual field progression had 3 to 9 year follow-up [11, 90, 157]. This contrasts with the original latanoprost studies using IOP reduction only as the end point, over 6 to 12 -month periods [32, 33, 233].

Progression of visual field defects is an important endpoint representing glaucomatous disease activity, as it has been shown that short term linear progression analysis is able to predict future progression [26]. Commonly, this is gauged in a subjective manner in the clinical context of the patient, but relies on observer experience. Objective progression analysis can be conducted in a trend-based, event-based or cluster-based manner. Trend-based analysis examines the variation in sensitivity within a complete series of visual field tests. Often change in mean deviation (MD) or visual field index (VFI) is analysed, however, global indices may be less specific for progression as certain points are affected more than others in glaucoma $[23,26$, 226]. Pointwise linear regression (PLR) is the most commonly used trend-based analysis, using a linear regression model to test the significance of change of sensitivity for each point in the field, such as PROGRESSOR software [241]. Developing from this, permutation analyses of pointwise linear regression (PoPLR) has since been shown to be able to provide an overall statistical significance value of an individual patient's visual field deterioration by comparing the observed series to many different order permutations [162]. In combining PLR with a binomial test, it has been proposed the results can also be improved in consistency [113]. Most 
recently, analysis with non-stationary Weibull error regression and spatial enhancement (ANSWERS) has been developed to take into account increasing variability in sensitivity as the differential light sensitivity reduces, as well as spatial correlation between test locations, providing increased sensitivity for visual field progression when compared to PoPLR [257]. Event-based analysis examines change from the baseline test and therefore requires fewer consecutive examinations. When change in sensitivity is outside that which would be physiologically expected, a point is registered as progressing. This approach has been used in the Glaucoma Progression Analysis (GPA) software which indicates pointwise levels of change in sensitivity [13] in addition to suggesting "possible" or "likely" progression according to the quantity of progressing points in a number of consecutive visits. When trend-based and event-based analyses are compared head to head, event-based GPA shows earlier and more sensitive detection of progression, with only moderate agreement with VFI [34]. Cluster-based analysis is a further variant used to detect progression in sensitivity of point clusters [37, 158]. This is to try to improve upon global indices which may provide inadequate sensitivity, and individual test point analysis susceptible to between-point dispersion and background noise $[144,161]$, and has been shown to correlate with the location of optic disc changes [30].

10-2 field tests are becoming increasingly recognised as a useful endpoint to detect paracentral visual field defects, often the most detrimental to quality of life [1]. This is due to the finding of significant paracentral visual field defects even in early glaucoma [64] [194, 221]. The superior sensitivity for parafoveal defects of 10-2 testing over 24-2 testing is achieved by having 68 points in the central \pm 10 degrees of visual field, in contrast to only 4 points in the central \pm 8 degrees in $24-2$, representing approximately $30 \%$ of retinal ganglion cells [49]. Significantly, up to $39.5 \%$ of glaucoma suspect eyes and $61.5 \%$ of glaucomatous eyes were found to contain central visual field abnormalities on 10-2 that were not detected with the 24- 
2 protocol [56]. This indicates that 10-2 visual fields may be a vastly underused endpoint in glaucoma. Pointwise linear progression analysis has also shown to have superior sensitivity using this protocol in patients with parafoveal scotomas [170] [57]. Furthermore, In advanced glaucoma, testing the remnants of the central papillo-macular bundle with a higher density of points is thought to be more valuable, compared to the standard 24-2 protocol $[189,234]$.

Frequency-doubling perimetry (FDP) uses high-frequency flickering (greater than $15 \mathrm{~Hz}$ ) that doubles the apparent spatial frequency of a grated target presented to the patient [9]. This method was originally thought to selectively test the function of large-diameter $\mathrm{M}_{\mathrm{y}}$ cells of the magnocellular ganglion cell pathway [143], however further work has cast doubt on this theory [237, 251]. Regardless of its exact mechanism, first- and second- generation FDP has shown promise both in screening and detection of early visual field defects. Whilst being more portable than a Humphrey field analyser enabling its use by mobile optometrists, the large targets also mean it is less affected by refractive error (up to 6 dioptres). Patients may also wear their own spectacles, with each eye only taking 30 seconds to 2 minutes to test (depending on visual field defects) compared to that of 4 to 7 minutes on Swedish Interactive Threshold Algorithm (SITA) 24-2 fast and standard protocols, respectively. In addition to these favourable practicalities, baseline characteristics have been shown to match and in some cases be superior to SAP, including improved reproducibility especially in areas of reduced sensitivity $[38,173,208]$. FDP testing locations have been adjusted to match the Humphrey 24-2 perimetry grid (Humphrey Matrix FDT perimeter, Carl Zeiss Meditec, Dublin, California, USA) allowing for head-to-head comparisons; significant diagnostic correlation was shown $(\mathrm{p}<0.001$ for MD and PSD) $[12,129]$. Again, FDP technology was able to match and even modestly improve the sensitivity in detecting early glaucomatous damage, [97, 110, 129, 137] however no improvement in monitoring progression of established glaucoma was found [96]. 
Microperimetry is a technique useful for testing retinal sensitivity in the context of poor fixation. Tracking fundus landmarks allows compensation for any eye movements during testing. Historically mainly used by macula specialists, this technique can also help in glaucoma patients with co-existent macular pathology or advanced centre-involving visual field defects. The Compass microperimeter (CenterVue, Padova, Italy) has been designed especially for this use, evaluating the central $30^{\circ}$ of retina [193]. In glaucoma, the remit of microperimetry has largely been in research to accurately monitor macular sensitivity in combination with ganglion cell complex imaging to better understand structure-function relationships [91]. Clinically, it has been shown to have better sensitivity than SAP for early field defects where corresponding OCT changes are found [134, 190].

Home monitoring of visual fields has become a possibility, given the increasing ownership of affordable computerised devices with high quality screens (in terms of viewing angles and resolution) $[14,210]$. By using these planar screens as a 'tangent' perimeter, the increased frequency of testing could expedite the 'learning curve' that patients undergo with such tests [76]. These could also serve to increase accessibility for housebound patients with home optometrist visits, and self-assessment. Examples which both demonstrate good correlation with SAP include the Melbourne Rapid Fields application [119] and the Visual Fields Easy app (George Kong Software) [111]. With integrated user-facing cameras in most mobile devices, there is also the potential for head and eye movement tracking to be incorporated into the testing procedure [111]. With regards to progression analysis, a computer model simulation has proposed that weekly home monitoring can increase the sensitivity with which we detect significant progression in mean deviation [8]. This may be made possible by improving retest variability with increased test frequency. The results suggested a sensitivity of $80 \%$ for detecting rapid field loss could be achieved in 0.9 years with weekly home monitoring (63\% 
home monitoring compliance) compared to 2.5 years with traditional 6-monthly clinic visits. This would provide a potentially significant lead-time in which to treat patients.

\section{Defining future biomarkers and outcomes}

\subsection{Detection of apoptosing retinal cells}

Glaucoma is a neurodegenerative disease similar to Alzheimer's, Parkinson's, and motor neuron diseases $[51,80]$. In glaucoma, visual loss is a result of apoptosis and death of retinal ganglion cells $[75,179,185]$ associated with progressive axonal loss and atrophy of the visual pathways $[85,250]$.

DARC (Detection of Apoptosing Retinal Cells) [44] is a novel technique which holds potential as a surrogate marker for glaucoma [47]. This technique uses fluorescently labelled Annexin 5 (ANX776) to visualise and quantify individual retinal cells undergoing apoptosis as a marker of disease activity. Whilst radiolabelled annexin has been used to quantify apoptosis in other tissue types such as in the myocardial infarct, brain and tumours [92, 126, 218], the resolution with which this can be detected in more opaque tissue types is uniquely surpassed in the eye due to its clear optical media, enabling single-cell resolution imaging. This might offer the opportunity to investigate the effect of apoptosis modulators, and the possibility of finding a reversibility window in the apoptosis and stress process during which to rescue cells marked for destruction [45].

ANX776, has so far been shown to be safe for human use and proven to demonstrate significantly higher DARC counts (total number of unique ANX776-labelled spots) in glaucoma patients compared to healthy controls (2.37-fold DARC count, $95 \%$ confidence interval: $1.4-4.03, \mathrm{P}=0.003$ ) [47]. As a possible endpoint, it potentially holds advantages over current gold-standard techniques in several respects; for 'pre-perimetric' patients, the potential for earlier diagnosis before irreversible field defects occur is suggested by post-hoc analysis 
demonstrating a significant relationship between DARC count and rate of progression [47]. In terms of its lack of susceptibility to patient-factors, DARC may be able to quantify the disease activity in those who are not able to complete a visual field test due to lack of comprehension or concentration ability. Patients with unusual disc morphologies such as in myopia, along with extremes of central corneal thickness and corneal pathology may also stand to benefit, however it is likely that significant corneal opacities would also prevent an accurate DARC count, although due to the fluorophore being in the NIR spectrum, its penetration is superior to 488 dyes.

DARC has been shown to possess the potential to trial new treatments, successfully demonstrating the effect of the known neuroprotective antioxidant, coenzyme Q10, in an experimental model. It was able to demonstrate a pressure-independent neuroprotective effect in rats, in keeping with post-mortem Brn3a histological assessment of whole retinal mounts [53]. Another study has used DARC in a rotenone-induced rodent model of Parkinson's disease, demonstrating the protective effect of rosiglitazone on neurodegeneration [160].

\subsection{Molecular biomarkers}

The role of genetic and molecular biomarkers in glaucoma has expanded with the increasing sophistication of laboratory techniques, high powered computer-aided analysis and statistical methods. In POAG, approximately $16-20 \%$ of disease risk has been attributed to genetic factors, with first and second degree relatives shown to be at increased risk [230, 243]. Through genome-wide association studies (GWAS), large numbers of genomes have been studied to compare single nucleotide polymorphisms (SNPs) in individuals with and without a disease

phenotype $[31,159]$. These studies have highlighted many susceptibility loci for POAG [19, $68,138,238]$ such as $T X N R D 2$ involved in mitochondrial function, ATXN2 which is implicated 
in other neurodegenerative disorders [66, 177], and FOXC1 important in anterior segment development (Axenfeld-Rieger syndrome). However, the number of specific gene biomarkers has so far been limited, with less than $10 \%$ of cases predicted to be due to specific mutation inheritance.

Examples of individual genes which have been associated with significant glaucoma risk include the myocilin (MYOC), optineurin $(O P T N)$ and TANK-binding kinase 1 (TBK1) genes. MYOC mutations have been associated with up to $36 \%$ of juvenile-onset open-angle glaucoma [86, 201, 232] compared to only 3 to $5 \%$ of all POAG cases [71]. It is expressed in most ocular tissues and has been proposed to be the culprit of a gain-of-function mutation causing abnormal protein aggregation and restriction of trabecular meshwork aqueous outflow [4, 101, 115, 240]. Furthermore, the autosomal dominant inheritance pattern has been shown to correlate to juvenile-onset cases, enabling earlier monitoring and prompt treatment when detected [206, 207]. Significantly, detection of $M Y O C$-related glaucoma patients has also led to the possibility of trialling gene therapy to treat this condition [102]. Animal models of $M Y O C$ mutations have shown contradictory results $[82,199]$. The $O P T N$ and $T B K 1$ mutations are also autosomal dominantly inherited and have been found to be associated with $1-2 \%$ of NTG cases $[5,17$, 192]. TBK1 genes represents a kinase protein that phosphorylates the autophagy receptor optineurin [155, 239] which is also implicated in amyotrophic lateral sclerosis, another neurodegenerative condition [147].

In contrast to this aforementioned minority, most of the inheritability of POAG is likely to be complex in nature, with certain polymorphisms associated with particular characteristics of the disease. For example, variants in cyclin-dependent kinase inhibitor $2 \mathrm{~B}(C D K N 2 B-A S 1)$ as well as the sineoculis homeobox homolog 1 and 6 genes (SIXI and SIX6) are associated with 
variation in cup-to-disc ratio [188]. Variants of the atonal homolog 7 region (ATOH7) are associated with optic disc size [142], and the transmembrane and coiled-coil domains 1 (TMCO1) and growth arrest-specific 7 (GAS7) are associated with variation in IOP [225]. Most crucially, TGFBR3-CDC7 has been associated with visual field progression (HR $6.71 \mathrm{p}=0.003$ ) [222] which in the future could serve as a useful biomarker in risk analysis with the increasing availability of genetic testing. As more genes are identified, these biomarkers can be implemented in animal models to test genotype-specific treatments [258] that may form a large part of the personalised medicine of the future. However, genetic testing must also be weighed up against the risk of over-diagnosis and over-treatment of patients with suspect genotype, but no evidence of disease [42].

In the case of pseudoexfoliative (PXF) glaucoma, the LOXL1 polymorphisms have been associated with disease [2, 219] [116] [65]. Given PXF glaucoma is often more aggressive $[83,88]$, this could potentially be useful in diagnosis and early treatment. However, PXF can also be detected on clinical examination therefore the clinical advantages of using genetic tests are yet to be validated. Furthermore, the difference in PXF prevalence in different populations is not explained by a corresponding difference in LOXL1 allele frequency, suggesting the regulatory genes controlling transcription of LOXL1 may be the real subject of interest [67]. Studies have shown changes in the rates of LOXL1 gene transcription and resultant protein formation in different stages of pseudoexfoliative glaucoma [195] indicating that measuring gene expression or lysyl oxidase concentrations could provide a future clinical surrogate marker of disease activity or even a treatment target.

Protein markers are used to monitor diseases in other areas of the body such as prostate cancer [133]. Proteins that are found to be upregulated in glaucomatous eyes are currently being used in research as targets for investigating pathogenesis and novel neuroprotective treatments. 
Those that have been associated with POAG are many, including apolipoprotein B and E [43], myotrophin and heat shock proteins including crystallins [215, 217]. One example is growth differentiation factor 15 (GDF15) which has been shown to increase in levels in the aqueous following RGC axonal injury, as well as being associated with worse visual fields [20]. Taking crystallins as another example, these are molecules expressed in the lens and retina and upregulated during retinal damage such as trauma, ischaemia and macular degeneration. Therefore they are thought to play an important role in retinal repair and axon regeneration $[141,217]$. In rat ocular hypertension models it has been shown that intravitreal crystallin injections have neuroprotective properties for retinal ganglion cells in terms of cell loss and nerve fibre layer thinning $[6,7]$.

Autoimmunity is thought to play an important role in the pathogenesis of neurological conditions such as multiple sclerosis [120] and Alzheimer's disease [50]. Therefore it is not surprising that many specific immune profiles and pro-inflammatory cytokines have been found to be present in glaucoma patients, in both blood and aqueous humour samples [84, 108, 109]. Specific IgG antibody patterns have been found in POAG, NTG and healthy individuals [108] indicating the potential role for immune screening and immune specific therapies in glaucoma $[22,197]$.

\subsection{Quality of life indicators}

The ultimate aim in preserving vision is to maintain quality of life (QoL) for patients. However using QoL as a surrogate marker in research or clinical practice is challenging as it is subjective, multifactorial, and can alter according to unpredictable timeframes [180]. In an effort to standardise QoL, questionnaires have been created relating to physical, emotional, psychological and social wellbeing, closely in line with the World Health Organisation's 
(WHO) definition of health: 'A state of complete physical, mental, and social well-being not merely the absence of disease' [166]. These include general quality of life questionnaires such as the WHO's WHOQOL [175, 203], and SF-36 [124, 242]. Vision-specific quality of life is assessed in more detail in patient-reported outcome measures such as the NEI-VFQ [167], independent mobility questionnaire [70], and the glaucoma-specific glaucoma symptom identifier [228] covering topics such as eye discomfort, drop side effects, and a variety of visual activities . It follows that we must take into account the effect of diagnosis and treatment on all aspects of physical, mental and social well-being when declaring treatment, a success in individual patients.

Correlation between QoL and visual field defects seems to be present in the majority of studies, especially those using vision-specific questionnaires [87, 167, 180]. However, those studies not involving patients in the advanced stages of disease showed little correlation with QoL scores, suggesting their limited ability to detect progression in the majority of patients [163]. Defects found to be most detrimental to quality of life were those developing in the second eye, causing difficulty in recognising faces, or affecting central inferior vision used for reading [1, 87]. It follows that similar-sized defects in different locations and in different patients may reduce QoL scores to varying extents, implying poor ability to act as a surrogate marker. Alternatively, patients may adapt to their field defects, with less detriment to a QoL score over time, as well as being subject to fluctuant mood disturbance which has also been found to correlate with patients' own perception of their visual function [104].

Although QoL scores are unlikely to prove useful in detecting glaucoma progression, they have been incorporated into large glaucoma trials such as the OHTS, CIGTS and AGIS, and can help us examine the effect of a diagnosis or treatment on a patient. Firstly, it appears that even the suspicion of glaucoma is associated with a possible deleterious effect on a patient's quality 
of life [242]. Once treatment is initiated, the effect of use of drops and their side-effects on quality of life can be quantified by specific patient-reported outcome measures (Comparison of Ophthalmic Medications for Tolerability - COMTOL [21] and the Treatment Satisfaction Survey-Intraocular Pressure PROM - TSS-IOP [16]). If patient satisfaction with the treatment is improved, the compliance is then also likely to be higher [54]. In the surgery vs. medical therapy conundrum, the CIGTS used a 'Symptom and Health Problem Checklist' with the Visual Activities Questionnaire (VAQ) [244] to show that quality of life was very comparable between those on medical therapy and those with initial surgical management [105]. In a clinical setting, quality of life scores may be useful in visual rehabilitation at an individual patient level to help practitioners support patients with their individual needs [167]. 


\section{Five-year view / Expert commentary}

Glaucoma research is now evolving into a multidisciplinary field, drawing together imaging, molecular medicine, neurodegeneration and informatics specialists. Further understanding of intraocular pressure control and progression analysis of visual field defects have been gained in the past few years, with imaging techniques becoming part of the routine standard of care. However, few new treatment strategies have come to light.

The confirmation that intraocular pressure is a poor surrogate marker has been key to highlight the need for new research into finding better biomarkers for glaucoma with which to trial novel therapies. Although there is good evidence supporting the role of intraocular pressure reduction in slowing glaucoma progression, we have little to suggest it is anything more than a modifiable risk factor as demonstrated in patients that progress despite optimum IOP lowering treatment, and in normal-tension glaucoma. In a shift away from investigating fluctuation in IOP as an important biomarker, future work may focus on the effect cardiovascular and endocrine diseases and pharmacological treatments have on the regulation and supply of perfusion to the optic nerve head. This in turn will bring together specialists in both the research and clinical settings to decipher to what extent the search for evermore effective treatments has on other, seemingly distant organ systems.

Imaging developments are likely to play a large role in the future development of glaucoma management. The most significant advance in biomarkers in the past few years has been the universal adoption of OCT technology which is now imaging deeper and at higher resolutions than ever before. As these boundaries expand, deeper and smaller structures are being characterised, which brings with it a steady stream of possible new biomarkers. Current examples of interest include characteristics of the choroid and lamina cribrosa. The ability to image blood flow in the retina, choroid and optic nerve without the use of contrast has begun 
to revolutionise medical retina practice, and may assume an important role in glaucoma with further uptake and developments of the technique.

Although visual field technology and progression analysis have come a long way since inception, the ceiling of their abilities has ultimately been limited by patient ability to carry out the test. In stark contrast, the possibility of objectively quantifying apoptosis in real-time using the DARC technique offers the exciting opportunity of capturing glaucomatous degeneration upstream, directly at the site of injury. By potentially compressing years of progression analysis into a single image, we can aim to prevent visual field defects from occurring as opposed to waiting for them to develop. This in turn will hopefully provide more people with certainty of diagnosis and better disasease management. With new investigations relying less on patient compliance or practitioner experience, we will simultaneously increase our capacity for rapidly expanding patient numbers, and potentially explore other neurodegenerative conditions through the eyes. The hope is that further studies validating this technique will enable its use in more accurately assessing the neuroprotective effect of novel therapies.

It is becoming clear that glaucoma is a heterogeneous group of diseases with a final common pathway leading to retinal ganglion cell death. The key to unlocking new treatments for glaucoma will be active collaboration between scientists and clinicians with varying specialist knowledge and skillsets. With the incorporation of artificial intelligence such as Deep Learning into medicine, we will soon be handling information with complexity above the level of human understanding. It is only by using a tight co-operative approach that we will have the chance of harnessing technology to provide new biomarkers and treatments. Whilst human life expectancy continues to increase, we must aim to sustain vision in order to complement longevity with quality of life. 

- The number of glaucoma sufferers worldwide is increasing rapidly and expected to reach 111.8 million by 2040 .

- The gold-standard for monitoring progression of disease is visual field testing which provides a good representation of visual impairment. However, irreversible defects can progress slowly and be complex to monitor. Furthermore, VF technology can be unreliable in a significant proportion of patients prompting new developments to improve its sensitivity and reproducibility.

- Intraocular pressure remains the only modifiable risk factor in glaucoma. Despite all currently available treatments having been proven using this biomarker, it remains an imperfect surrogate for glaucoma progression.

- The number of potential imaging biomarkers is increasing rapidly with the development of swept-source OCT and adaptive optics, able to image the posterior surface of the lamina cribrosa and the choroid, with increased resolution.

- Widespread ownership of electronic devices with high quality screens and cameras is opening up opportunities for home monitoring and virtual clinics.

- Glaucoma is increasingly being recognised as a neurodegenerative condition, and we now have a technique (DARC, Detection of Apoptosing Retinal Cells) that has the potential to directly measure disease activity by visualisation of retinal ganglion cell apoptosis.

- Genome wide association studies and advances in molecular biology have unearthed many gene loci, proteins and antibodies inferring glaucoma risk and pathogenesis. However, as yet few of these findings have provided a viable screening tool.

\section{- References}



Impact of Location of Progressive Visual Field Loss on Longitudinal Changes in Quality of Life of Patients with Glaucoma. Ophthalmology 123: 552-557 Doi 10.1016/j.ophtha.2015.10.046 SA (2010) Analysis of LOXL1 polymorphisms in a Saudi Arabian population with pseudoexfoliation glaucoma. Mol Vis 16: 2805-2810

Alasil T, Wang K, Yu F, Field MG, Lee H, Baniasadi N, de Boer JF, Coleman AL, Chen TC (2014) Correlation of retinal nerve fiber layer thickness and visual fields in glaucoma: a broken stick model. Am J Ophthalmol 157: 953-959 Doi 10.1016/j.ajo.2014.01.014

Allingham RR, Wiggs JL, De La Paz MA, Vollrath D, Tallett DA, Broomer B, Jones KH, Del Bono EA, Kern J, Patterson Ket al (1998) Gln368STOP myocilin mutation in families with late-onset primary open-angle glaucoma. Invest Ophthalmol Vis Sci 39: 2288-2295

Alward WLM, Kwon YH, Kawase K, Craig JE, Hayreh SS, Johnson AT, Khanna CL, Yamamoto T, Mackey DA, Roos BRet al (2003) Evaluation of optineurin sequence variations in 1,048 patients with open-angle glaucoma. Am J Ophthalmol 136: 904910

6 Anders F, Liu A, Mann C, Teister J, Lauzi J, Thanos S, Grus FH, Pfeiffer N, Prokosch V (2017) The Small Heat Shock Protein alpha-Crystallin B Shows Neuroprotective Properties in a Glaucoma Animal Model. Int J Mol Sci 18: Doi 10.3390/ijms 18112418

7 Anders F, Teister J, Liu A, Funke S, Grus FH, Thanos S, von Pein HD, Pfeiffer N, Prokosch V (2017) Intravitreal injection of beta-crystallin B2 improves retinal ganglion cell survival in an experimental animal model of glaucoma. PLoS One 12: e0175451 Doi 10.1371/journal.pone.0175451

Anderson AJ, Bedggood PA, Kong YXG, Martin KR, Vingrys AJ (2017) Can Home Monitoring Allow Earlier Detection of Rapid Visual Field Progression in Glaucoma? Ophthalmology 0: Doi 10.1016/j.ophtha.2017.06.028

9 Anderson AJ, Johnson CA (2003) Frequency-doubling technology perimetry. Ophthalmol Clin North Am 16: 213-225

10 Anderson DR, Hendrickson A (1974) Effect of intraocular pressure on rapid axoplasmic transport in monkey optic nerve. Invest Ophthalmol 13: 771-783

11 Anderson DR, Normal Tension Glaucoma Study (2003) Collaborative normal tension glaucoma study. Curr Opin Ophthalmol 14: 86-90

12 Artes PH, Hutchison DM, Nicolela MT, LeBlanc RP, Chauhan BC (2005) Threshold and variability properties of matrix frequency-doubling technology and standard automated perimetry in glaucoma. Invest Ophthalmol Vis Sci 46: 2451-2457 Doi 10.1167/iovs.05-0135

13 Artes PH, O'Leary N, Nicolela MT, Chauhan BC, Crabb DP (2014) Visual field progression in glaucoma: what is the specificity of the Guided Progression Analysis? Ophthalmology 121: 2023-2027 Doi 10.1016/j.ophtha.2014.04.015

14 Aslam TM, Murray IJ, Lai MY, Linton E, Tahir HJ, Parry NR (2013) An assessment of a modern touch-screen tablet computer with reference to core physical characteristics necessary for clinical vision testing. J R Soc Interface 10: 20130239 Doi 10.1098/rsif.2013.0239

15 Asrani S, Zeimer R, Wilensky J, Gieser D, Vitale S, Lindenmuth K (2000) Large diurnal fluctuations in intraocular pressure are an independent risk factor in patients with glaucoma. J Glaucoma 9: 134-142 
16 Atkinson MJ, Stewart WC, Fain JM, Stewart JA, Dhawan R, Mozaffari E, Lohs J (2003) A new measure of patient satisfaction with ocular hypotensive medications: the Treatment Satisfaction Survey for Intraocular Pressure (TSS-IOP). Health Qual Life Outcomes 1: 67 Doi 10.1186/1477-7525-1-67

17 Aung T, Ebenezer ND, Brice G, Child AH, Prescott Q, Lehmann OJ, Hitchings RA, Bhattacharya SS (2003) Prevalence of optineurin sequence variants in adult primary open angle glaucoma: implications for diagnostic testing. J Med Genet 40: e101

18 Azuara-Blanco A, Katz LJ, Spaeth GL, Vernon SA, Spencer F, Lanzl IM (2003) Clinical agreement among glaucoma experts in the detection of glaucomatous changes of the optic disk using simultaneous stereoscopic photographs. Am J Ophthalmol 136: 949-950

19 Bailey JNC, Loomis SJ, Kang JH, Allingham RR, Gharahkhani P, Khor CC, Burdon KP, Aschard H, Chasman DI, Igo RPet al (2016) Genome-wide association analysis identifies TXNRD2, ATXN2 and FOXC1 as susceptibility loci for primary openangle glaucoma. Nat Genet 48: 189-194 Doi 10.1038/ng.3482

20 Ban N, Siegfried CJ, Lin JB, Shui YB, Sein J, Pita-Thomas W, Sene A, Santeford A, Gordon M, Lamb Ret al (2017) GDF15 is elevated in mice following retinal ganglion cell death and in glaucoma patients. JCI Insight 2: Doi 10.1172/jci.insight.91455

21 Barber BL, Strahlman ER, Laibovitz R, Guess HA, Reines SA (1997) Validation of a questionnaire for comparing the tolerability of ophthalmic medications. Ophthalmology 104: 334-342

22 Baudouin C, Liang H (2006) [Vaccine for glaucoma, myth or reality?]. J Fr Ophtalmol 29 Spec No 2: 9-12

23 Bengtsson B, Heijl A (2008) A visual field index for calculation of glaucoma rate of progression. Am J Ophthalmol 145: 343-353 Doi 10.1016/j.ajo.2007.09.038

24 Bengtsson B, Heijl A, Olsson J (1998) Evaluation of a new threshold visual field strategy, SITA, in normal subjects. Swedish Interactive Thresholding Algorithm. Acta Ophthalmol Scand 76: 165-169

25 Bengtsson B, Leske MC, Hyman L, Heijl A, Early Manifest Glaucoma Trial G (2007) Fluctuation of intraocular pressure and glaucoma progression in the early manifest glaucoma trial. Ophthalmology 114: 205-209 Doi 10.1016/j.ophtha.2006.07.060

26 Bengtsson B, Patella VM, Heijl A (2009) Prediction of glaucomatous visual field loss by extrapolation of linear trends. Arch Ophthalmol 127: 1610-1615 Doi 10.1001/archophthalmol.2009.297

27 Berger VW (2004) Does the Prentice criterion validate surrogate endpoints? Stat Med 23: 1571-1578 Doi 10.1002/sim.1780

28 Biomarkers Definitions Working Group. (2001) Biomarkers and surrogate endpoints: preferred definitions and conceptual framework. Clin Pharmacol Ther 69: 89-95 Doi 10.1067/mcp.2001.113989

29 Blumenthal EZ, Horani A, Sasikumar R, Garudadri C, Udaykumar A, Thomas R (2006) Correlating structure with function in end-stage glaucoma. Ophthalmic Surg Lasers Imaging 37: 218-223

30 Bono V, Normando EM, Davis B, Crawley L, Ahmed F, Cillino S, Bloom P, Cordeiro MF (2015) Cluster visual field progression and its relationship with optic disc changes. Investigative Ophthalmology \& Visual Science 56: 1044-1044

31 Burdon KP, Macgregor S, Hewitt AW, Sharma S, Chidlow G, Mills RA, Danoy P, Casson R, Viswanathan AC, Liu JZet al (2011) Genome-wide association study identifies susceptibility loci for open angle glaucoma at TMCO1 and CDKN2B-AS1. Nat Genet 43: 574-578 Doi 10.1038/ng.824 
32 Camras CB (1996) Comparison of latanoprost and timolol in patients with ocular hypertension and glaucoma: a six-month masked, multicenter trial in the United States. The United States Latanoprost Study Group. Ophthalmology 103: 138-147

33 Camras CB, Alm A, Watson P, Stjernschantz J (1996) Latanoprost, a prostaglandin analog, for glaucoma therapy. Efficacy and safety after 1 year of treatment in 198 patients. Latanoprost Study Groups. Ophthalmology 103: 1916-1924

34 Casas-Llera P, Rebolleda G, Munoz-Negrete FJ, Arnalich-Montiel F, Perez-Lopez M, Fernandez-Buenaga R (2009) Visual field index rate and event-based glaucoma progression analysis: comparison in a glaucoma population. Br J Ophthalmol 93: 1576-1579 Doi 10.1136/bjo.2009.158097

35 Chang RT, Knight ORJ, Feuer WJ, Budenz DL (2009) Sensitivity and specificity of time-domain versus spectral-domain optical coherence tomography in diagnosing early to moderate glaucoma. Ophthalmology 116: 2294-2299 Doi 10.1016/j.ophtha.2009.06.012

36 Chauhan BC, Garway-Heath DF, Goñi FJ, Rossetti L, Bengtsson B, Viswanathan AC, Heijl A (2008) Practical recommendations for measuring rates of visual field change in glaucoma. Br J Ophthalmol 92: 569-573 Doi 10.1136/bjo.2007.135012

37 Chauhan BC, Henson DB, Hobley AJ (1988) Cluster analysis in visual field quantification. Doc Ophthalmol 69: 25-39

38 Chauhan BC, Johnson CA (1999) Test-retest variability of frequency-doubling perimetry and conventional perimetry in glaucoma patients and normal subjects. Invest Ophthalmol Vis Sci 40: 648-656

39 Chauhan BC, LeBlanc RP, McCormick TA, Rogers JB (1994) Test-Retest Variability of Topographic Measurements With Confocal Scanning Laser Tomography in Patients With Glaucoma and Control Subjects. American Journal of Ophthalmology 118: 9-15 Doi 10.1016/S0002-9394(14)72836-3

40 Chauhan BC, Nicolela MT, Artes PH (2009) Incidence and rates of visual field progression after longitudinally measured optic disc change in glaucoma. Ophthalmology 116: 2110-2118 Doi 10.1016/j.ophtha.2009.04.031

41 Cherecheanu AP, Garhofer G, Schmidl D, Werkmeister R, Schmetterer L (2013) Ocular perfusion pressure and ocular blood flow in glaucoma. Curr Opin Pharmacol 13: 36-42 Doi 10.1016/j.coph.2012.09.003

42 Collier R (2012) The downside of genetic screening. CMAJ 184: 862-864 Doi 10.1503/cmaj.109-4169

43 Copin B, Brezin AP, Valtot F, Dascotte JC, Bechetoille A, Garchon HJ (2002) Apolipoprotein E-promoter single-nucleotide polymorphisms affect the phenotype of primary open-angle glaucoma and demonstrate interaction with the myocilin gene. Am J Hum Genet 70: 1575-1581 Doi 10.1086/340733

44 Cordeiro MF (2007) DARC: a new method for detecting progressive neuronal death. Eye: S15 Doi 10.1038/sj.eye.6702881

45 Cordeiro MF, Guo L, Luong V, Harding G, Wang W, Jones HE, Moss SE, Sillito AM, Fitzke FW (2004) Real-time imaging of single nerve cell apoptosis in retinal neurodegeneration. Proceedings of the National Academy of Sciences of the United States of America 101: 13352-13356 Doi 10.1073/pnas.0405479101

46 Cordeiro MF, Levin LA (2011) Clinical evidence for neuroprotection in glaucoma. Am J Ophthalmol 152: 715-716 Doi 10.1016/j.ajo.2011.06.015

$47 \quad * *$ Cordeiro MF, Normando EM, Cardoso MJ, Miodragovic S, Jeylani S, Davis BM, Guo L, Ourselin S, A'Hern R, Bloom PA (2017) Real-time imaging of single neuronal cell apoptosis in patients with glaucoma. Brain 140: 1757-1767 Doi 10.1093/brain/awx088 
** This is a proof-of-concept study proposing the realtime visualisation of retinal ganglion cell apoptosis in humans. Initial results have demonstrated significant differences between progressing glaucoma patients and healthy controls. Post-hoc analysis also revealed the ability to predict future progression.

48 Court JH, Austin MW (2015) Virtual glaucoma clinics: patient acceptance and quality of patient education compared to standard clinics. Clin Ophthalmol 9: 745-749 Doi 10.2147/OPTH.S75000

49 Curcio CA, Allen KA (1990) Topography of ganglion cells in human retina. J Comp Neurol 300: 5-25 Doi 10.1002/cne.903000103

50 D'Andrea MR (2005) Evidence that immunoglobulin-positive neurons in Alzheimer's disease are dying via the classical antibody-dependent complement pathway. Am J Alzheimers Dis Other Demen 20: 144-150 Doi 10.1177/153331750502000303

51 Danesh-Meyer HV, Levin LA (2015) Glaucoma as a neurodegenerative disease. J Neuroophthalmol 35 Suppl 1: S22-28 Doi 10.1097/WNO.0000000000000293

52 David R, Zangwill L, Briscoe D, Dagan M, Yagev R, Yassur Y (1992) Diurnal intraocular pressure variations: an analysis of 690 diurnal curves. Br J Ophthalmol 76: 280-283

53 Davis BM, Tian K, Pahlitzsch M, Brenton J, Ravindran N, Butt G, Malaguarnera G, Normando EM, Guo L, Cordeiro MF (2017) Topical Coenzyme Q10 demonstrates mitochondrial-mediated neuroprotection in a rodent model of ocular hypertension. Mitochondrion 36: 114-123 Doi 10.1016/j.mito.2017.05.010

54 Day DG, Sharpe ED, Atkinson MJ, Stewart JA, Stewart WC (2006) The clinical validity of the treatment satisfaction survey for intraocular pressure in ocular hypertensive and glaucoma patients. Eye (Lond) 20: 583-590 Doi 10.1038/sj.eye.6701932

55 De Gruttola VG, Clax P, DeMets DL, Downing GJ, Ellenberg SS, Friedman L, Gail MH, Prentice R, Wittes J, Zeger SL (2001) Considerations in the evaluation of surrogate endpoints in clinical trials. summary of a National Institutes of Health workshop. Control Clin Trials 22: 485-502

56 **De Moraes CG, Hood DC, Thenappan A, Girkin CA, Medeiros FA, Weinreb RN, Zangwill LM, Liebmann JM (2017) 24-2 Visual Fields Miss Central Defects Shown on 10-2 Tests in Glaucoma Suspects, Ocular Hypertensives, and Early Glaucoma. Ophthalmology 124: 1449-1456 Doi 10.1016/j.ophtha.2017.04.021

** This prospective cross-sectional study demonstrated 10-2 visual fields detected significiantly more early glaucomatous defects than conventional 242 testing, suggesting this method is underused in current practice.

57 de Moraes CG, Song C, Liebmann JM, Simonson JL, Furlanetto RL, Ritch R (2014) Defining 10-2 visual field progression criteria: exploratory and confirmatory factor analysis using pointwise linear regression. Ophthalmology 121: 741-749 Doi 10.1016/j.ophtha.2013.10.018

58 DeLeón Ortega JE, Sakata LM, Kakati B, McGwin G, Monheit BE, Arthur SN, Girkin CA (2007) Effect of glaucomatous damage on repeatability of confocal scanning laser ophthalmoscope, scanning laser polarimetry, and optical coherence tomography. Invest Ophthalmol Vis Sci 48: 1156-1163 Doi 10.1167/iovs.06-0921

59 Dong ZM, Wollstein G, Wang B, Schuman JS (2017) Adaptive optics optical coherence tomography in glaucoma. Prog Retin Eye Res 57: 76-88 Doi 10.1016/j.preteyeres.2016.11.001

60 Downs JC (2015) IOP telemetry in the nonhuman primate. Exp Eye Res 141: 91-98 Doi 10.1016/j.exer.2015.07.015 
61 Downs JC, Burgoyne CF, Seigfreid WP, Reynaud JF, Strouthidis NG, Sallee V (2011) 24-hour IOP telemetry in the nonhuman primate: implant system performance and initial characterization of IOP at multiple timescales. Invest Ophthalmol Vis Sci 52: 7365-7375 Doi 10.1167/iovs.11-7955

$62 * *$ Downs JC, Girkin CA (2017) Lamina cribrosa in glaucoma. Curr Opin Ophthalmol 28: 113-119 Doi 10.1097/ICU.0000000000000354

** This review summarises the latest technology and knowledge regarding imaging of structural changes of the lamina cribrosa in glaucoma, providing possible new surrogate markers.

63 Drance SM (1999) The Collaborative Normal-Tension Glaucoma Study and some of its lessons. Can J Ophthalmol 34: 1-6

64 Drance SM (1969) The early field defects in glaucoma. Invest Ophthalmol 8: 84-91

65 Dubey SK, Hejtmancik JF, Krishnadas SR, Sharmila R, Haripriya A, Sundaresan P (2014) Lysyl oxidase-like 1 gene in the reversal of promoter risk allele in pseudoexfoliation syndrome. JAMA Ophthalmol 132: 949-955 Doi 10.1001/jamaophthalmol.2014.845

66 Elden AC, Kim H-J, Hart MP, Chen-Plotkin AS, Johnson BS, Fang X, Armakola M, Geser F, Greene R, Lu MMet al (2010) Ataxin-2 intermediate-length polyglutamine expansions are associated with increased risk for ALS. Nature 466: 1069-1075 Doi 10.1038/nature09320

67 Fan BJ, Pasquale LR, Rhee D, Li T, Haines JL, Wiggs JL (2011) LOXL1 promoter haplotypes are associated with exfoliation syndrome in a U.S. Caucasian population. Invest Ophthalmol Vis Sci 52: 2372-2378 Doi 10.1167/iovs.10-6268

68 Fan BJ, Wang DY, Lam DSC, Pang CP (2006) Gene mapping for primary open angle glaucoma. Clin Biochem 39: 249-258 Doi 10.1016/j.clinbiochem.2005.11.001

69 Fan N, Wang P, Tang L, Liu X (2015) Ocular Blood Flow and Normal Tension Glaucoma. Biomed Res Int 2015: 308505 Doi 10.1155/2015/308505

70 Fenwick EK, O'Hare F, Deverell L, Ayton LN, Luu CD, McSweeney S, Bentley SA, Guymer RH, Finger RP (2016) Rasch Analysis of the Independent Mobility Questionnaire. Optom Vis Sci 93: 181-187 Doi 10.1097/OPX.0000000000000787

71 Fingert JH, Héon E, Liebmann JM, Yamamoto T, Craig JE, Rait J, Kawase K, Hoh ST, Buys YM, Dickinson Jet al (1999) Analysis of myocilin mutations in 1703 glaucoma patients from five different populations. Hum Mol Genet 8: 899-905

72 Flaxman SR, Bourne RRA, Resnikoff S, Ackland P, Braithwaite T, Cicinelli MV, Das A, Jonas JB, Keeffe J, Kempen JHet al (2017) Global causes of blindness and distance vision impairment 1990-2020: a systematic review and meta-analysis. Lancet Glob Health: Doi 10.1016/S2214-109X(17)30393-5

73 Fleming TR, DeMets DL (1996) Surrogate end points in clinical trials: are we being misled? Ann Intern Med 125: 605-613

74 Furlanetto RL, Park SC, Damle UJ, Sieminski SF, Kung Y, Siegal N, Liebmann JM, Ritch R (2013) Posterior displacement of the lamina cribrosa in glaucoma: in vivo interindividual and intereye comparisons. Invest Ophthalmol Vis Sci 54: 4836-4842 Doi 10.1167/iovs.12-11530

75 Garcia-Valenzuela E, Shareef S, Walsh J, Sharma SC (1995) Programmed cell death of retinal ganglion cells during experimental glaucoma. Exp Eye Res 61: 33-44

76 Gardiner SK, Demirel S, Johnson CA (2008) Is there evidence for continued learning over multiple years in perimetry? Optom Vis Sci 85: 1043-1048 Doi 10.1097/OPX.0b013e31818b9b40

77 Gardiner SK, Fortune B, Wang L, Downs JC, Burgoyne CF (2012) Intraocular pressure magnitude and variability as predictors of rates of structural change in non- 
human primate experimental glaucoma. Exp Eye Res 103: 1-8 Doi 10.1016/j.exer.2012.07.012

$78 * *$ Garway-Heath DF, Crabb DP, Bunce C, Lascaratos G, Amalfitano F, Anand N, Azuara-Blanco A, Bourne RR, Broadway DC, Cunliffe IAet al (2015) Latanoprost for open-angle glaucoma (UKGTS): a randomised, multicentre, placebo-controlled trial. Lancet 385: 1295-1304 Doi 10.1016/S0140-6736(14)62111-5

**The first POAG randomised placebo-controlled trial showing significant visual field preservation by an IOP lowering drug. Significaintly, this was accomplished with a short 24-month follow up duration.

79 Gautam N, Kaur S, Kaushik S, Raj S, Pandav SS (2016) Postural and diurnal fluctuations in intraocular pressure across the spectrum of glaucoma. Br J Ophthalmol 100: 537-541 Doi 10.1136/bjophthalmol-2015-306861

80 Gauthier AC, Liu J (2016) Neurodegeneration and Neuroprotection in Glaucoma. Yale J Biol Med 89: 73-79

81 Gmeiner JM, Schrems WA, Mardin CY, Laemmer R, Kruse FE, Schrems-Hoesl LM (2016) Comparison of Bruch's Membrane Opening Minimum Rim Width and Peripapillary Retinal Nerve Fiber Layer Thickness in Early Glaucoma Assessment. Invest Ophthalmol Vis Sci 57: OCT575-584 Doi 10.1167/iovs.15-18906

82 Gould DB, Reedy M, Wilson LA, Smith RS, Johnson RL, John SWM (2006) Mutant myocilin nonsecretion in vivo is not sufficient to cause glaucoma. Mol Cell Biol 26: 8427-8436 Doi 10.1128/MCB.01127-06

83 Grodum K, Heijl A, Bengtsson B (2005) Risk of glaucoma in ocular hypertension with and without pseudoexfoliation. Ophthalmology 112: 386-390 Doi 10.1016/j.ophtha.2004.09.024

84 Grus FH, Joachim SC, Wuenschig D, Rieck J, Pfeiffer N (2008) Autoimmunity and glaucoma. J Glaucoma 17: 79-84 Doi 10.1097/IJG.0b013e318156a592

85 Gupta N, Ang L-C, Noël de Tilly L, Bidaisee L, Yücel YH (2006) Human glaucoma and neural degeneration in intracranial optic nerve, lateral geniculate nucleus, and visual cortex. Br J Ophthalmol 90: 674-678 Doi 10.1136/bjo.2005.086769

86 Gupta V, Somarajan BI, Gupta S, Chaurasia AK, Kumar S, Dutta P, Gupta V, Sharma A, Tayo BO, Nischal K (2017) The inheritance of juvenile onset primary open angle glaucoma. Clin Genet 92: 134-142 Doi 10.1111/cge.12906

87 Gutierrez P, Wilson MR, Johnson C, Gordon M, Cioffi GA, Ritch R, Sherwood M, Meng K, Mangione CM (1997) Influence of glaucomatous visual field loss on healthrelated quality of life. Arch Ophthalmol 115: 777-784

88 Heijl A, Bengtsson B, Hyman L, Leske MC, Early Manifest Glaucoma Trial G (2009) Natural history of open-angle glaucoma. Ophthalmology 116: 2271-2276 Doi 10.1016/j.ophtha.2009.06.042

89 Heijl A, Buchholz P, Norrgren G, Bengtsson B (2013) Rates of visual field progression in clinical glaucoma care. Acta Ophthalmol 91: 406-412 Doi 10.1111/j.1755-3768.2012.02492.x

90 Heijl A, Leske MC, Bengtsson B, Hyman L, Bengtsson B, Hussein M, Early Manifest Glaucoma Trial Group (2002) Reduction of intraocular pressure and glaucoma progression: results from the Early Manifest Glaucoma Trial. Arch Ophthalmol 120: 1268-1279

91 Hirooka K, Misaki K, Nitta E, Ukegawa K, Sato S, Tsujikawa A (2016) Comparison of Macular Integrity Assessment (MAIA ), MP-3, and the Humphrey Field Analyzer in the Evaluation of the Relationship between the Structure and Function of the Macula. PLoS One 11: e0151000 Doi 10.1371/journal.pone.0151000 
92 Hoebers FJP, Kartachova M, de Bois J, van den Brekel MWM, van Tinteren H, van Herk M, Rasch CRN, Valdés Olmos RA, Verheij M (2008) 99mTc Hynic-rh-Annexin $\mathrm{V}$ scintigraphy for in vivo imaging of apoptosis in patients with head and neck cancer treated with chemoradiotherapy. Eur J Nucl Med Mol Imaging 35: 509-518 Doi $10.1007 / \mathrm{s} 00259-007-0624-\mathrm{x}$

$93 \quad * *$ Holló G (2017) Influence of Large Intraocular Pressure Reduction on Peripapillary OCT Vessel Density in Ocular Hypertensive and Glaucoma Eyes. J Glaucoma 26: e7e10 Doi 10.1097/IJG.0000000000000527

** This study is the latest to show the promise of OCTA in monitoring the response to lowering intraocular pressure

94 Holló G (2016) Intrasession and Between-Visit Variability of Sector Peripapillary Angioflow Vessel Density Values Measured with the Angiovue Optical Coherence Tomograph in Different Retinal Layers in Ocular Hypertension and Glaucoma. PLoS One 11: e0161631 Doi 10.1371/journal.pone.0161631

95 Holló G (2017) Relationship Between OCT Angiography Temporal Peripapillary Vessel-Density and Octopus Perimeter Paracentral Cluster Mean Defect. J Glaucoma 26: 397-402 Doi 10.1097/IJG.0000000000000630

$96 \mathrm{Hu}$ R, Wang C, Gu Y, Racette L (2016) Comparison of Standard Automated Perimetry, Short-Wavelength Automated Perimetry, and Frequency-Doubling Technology Perimetry to Monitor Glaucoma Progression. Medicine (Baltimore) 95: e2618 Doi 10.1097/MD.0000000000002618

97 Hu R, Wang C, Racette L (2017) Comparison of matrix frequency-doubling technology perimetry and standard automated perimetry in monitoring the development of visual field defects for glaucoma suspect eyes. PLoS One 12: e0178079 Doi 10.1371/journal.pone.0178079

98 Huang XR, Zhou Y, Kong W, Knighton RW (2011) Reflectance decreases before thickness changes in the retinal nerve fiber layer in glaucomatous retinas. Invest Ophthalmol Vis Sci 52: 6737-6742 Doi 10.1167/iovs.11-7665

99 Hwang YH, Kim YY (2012) Effect of peripapillary vitreous opacity on retinal nerve fiber layer thickness measurement using optical coherence tomography. Arch Ophthalmol 130: 789-792 Doi 10.1001/archophthalmol.2011.2517

100 Investigators A (2000) The Advanced Glaucoma Intervention Study (AGIS): 7. The relationship between control of intraocular pressure and visual field deterioration. The AGIS Investigators. Am J Ophthalmol 130: 429-440

101 Jacobson N, Andrews M, Shepard AR, Nishimura D, Searby C, Fingert JH, Hageman G, Mullins R, Davidson BL, Kwon YHet al (2001) Non-secretion of mutant proteins of the glaucoma gene myocilin in cultured trabecular meshwork cells and in aqueous humor. Hum Mol Genet 10: 117-125

102 Jain A, Zode G, Kasetti RB, Ran FA, Yan W, Sharma TP, Bugge K, Searby CC, Fingert JH, Zhang Fet al (2017) CRISPR-Cas9-based treatment of myocilinassociated glaucoma. Proc Natl Acad Sci U S A 114: 11199-11204 Doi 10.1073/pnas.1706193114

103 Jamal KN, Gürses-Ozden R, Liebmann JM, Ritch R (2002) Attempted eyelid closure affects intraocular pressure measurement in open-angle glaucoma patients. Am J Ophthalmol 134: 186-189

104 Jampel HD, Frick KD, Janz NK, Wren PA, Musch DC, Rimal R, Lichter PR, CIGTS Study Group ( 2007) Depression and mood indicators in newly diagnosed glaucoma patients. Am J Ophthalmol 144: 238-244 Doi 10.1016/j.ajo.2007.04.048

105 Janz NK, Wren PA, Lichter PR, Musch DC, Gillespie BW, Guire KE, Mills RP, CIGTS Study Group (2001) The Collaborative Initial Glaucoma Treatment Study: 
interim quality of life findings after initial medical or surgical treatment of glaucoma. Ophthalmology 108: 1954-1965

106 Jia Y, Wei E, Wang X, Zhang X, Morrison JC, Parikh M, Lombardi LH, Gattey DM, Armour RL, Edmunds Bet al (2014) Optical coherence tomography angiography of optic disc perfusion in glaucoma. Ophthalmology 121: 1322-1332 Doi 10.1016/j.ophtha.2014.01.021

107 Jian Y, Lee S, Ju MJ, Heisler M, Ding W, Zawadzki RJ, Bonora S, Sarunic MV (2016) Lens-based wavefront sensorless adaptive optics swept source OCT. Sci Rep 6: 27620 Doi 10.1038/srep27620

108 Joachim SC, Pfeiffer N, Grus FH (2005) Autoantibodies in patients with glaucoma: a comparison of IgG serum antibodies against retinal, optic nerve, and optic nerve head antigens. Graefes Arch Clin Exp Ophthalmol 243: 817-823 Doi 10.1007/s00417-0041094-5

109 Joachim SC, Reichelt J, Berneiser S, Pfeiffer N, Grus FH (2008) Sera of glaucoma patients show autoantibodies against myelin basic protein and complex autoantibody profiles against human optic nerve antigens. Graefes Arch Clin Exp Ophthalmol 246: 573-580 Doi 10.1007/s00417-007-0737-8

110 Johnson CA, Cioffi GA, Van Buskirk EM (1999) Frequency doubling technology perimetry using a 24--2 stimulus presentation pattern. Optom Vis Sci 76: 571-581

111 Johnson CA, Thapa S, George Kong YX, Robin AL (2017) Performance of an iPad Application to Detect Moderate and Advanced Visual Field Loss in Nepal. Am J Ophthalmol 182: 147-154 Doi 10.1016/j.ajo.2017.08.007

112 Jonas JB, Schmidt AM, Müller-Bergh JA, Schlötzer-Schrehardt UM, Naumann GO (1992) Human optic nerve fiber count and optic disc size. Invest Ophthalmol Vis Sci 33: 2012-2018

113 Karakawa A, Murata H, Hirasawa H, Mayama C, Asaoka R (2013) Detection of progression of glaucomatous visual field damage using the point-wise method with the binomial test. PLoS One 8: e78630 Doi 10.1371/journal.pone.0078630

114 *Kass MA, Heuer DK, Higginbotham EJ, Johnson CA, Keltner JL, Miller JP, Parrish RK, Wilson MR, Gordon MO (2002) The Ocular Hypertension Treatment Study: a randomized trial determines that topical ocular hypotensive medication delays or prevents the onset of primary open-angle glaucoma. Arch Ophthalmol 120: 701-713; discussion 829-730

* This landmark glaucoma trial was the first to clearly demonstrate the benefits of treating intraocular pressure. In 1,636 patients with ocular hypertension it was shown the risk of progression to glaucoma reduces from $9.5 \%$ to $4.4 \%$ on treate as measured with visual fields and optic disc photographs

115 Kim BS, Savinova OV, Reedy MV, Martin J, Lun Y, Gan L, Smith RS, Tomarev SI, John SW, Johnson RL (2001) Targeted Disruption of the Myocilin Gene (Myoc) Suggests that Human Glaucoma-Causing Mutations Are Gain of Function. Mol Cell Biol 21: 7707-7713 Doi 10.1128/MCB.21.22.7707-7713.2001

116 Kim S, Kim Y (2012) Variations in LOXL1 associated with exfoliation glaucoma do not affect amine oxidase activity. Mol Vis 18: 265-270

117 Kocaoglu OP, Cense B, Jonnal RS, Wang Q, Lee S, Gao W, Miller DT (2011) Imaging retinal nerve fiber bundles using optical coherence tomography with adaptive optics. Vision Res 51: 1835-1844 Doi 10.1016/j.visres.2011.06.013

118 Kocaoglu OP, Turner TL, Liu Z, Miller DT (2014) Adaptive optics optical coherence tomography at $1 \mathrm{MHz}$. Biomed Opt Express 5: 4186-4200 Doi 10.1364/BOE.5.004186 
119 Kong YXG, He M, Crowston JG, Vingrys AJ ( 2016) A Comparison of Perimetric Results from a Tablet Perimeter and Humphrey Field Analyzer in Glaucoma Patients. Transl Vis Sci Technol 5: 2 Doi 10.1167/tvst.5.6.2

120 Korn T (2008) Pathophysiology of multiple sclerosis. J Neurol 255 Suppl 6: 2-6 Doi $10.1007 / \mathrm{s} 00415-008-6001-2$

121 Koutsonas A, Walter P, Roessler G, Plange N (2015) Implantation of a novel telemetric intraocular pressure sensor in patients with glaucoma (ARGOS study): 1year results. Invest Ophthalmol Vis Sci 56: 1063-1069 Doi 10.1167/iovs.14-14925

122 Krupin T, Liebmann JM, Greenfield DS, Ritch R, Gardiner S, Low-Pressure Glaucoma Study Group (2011) A randomized trial of brimonidine versus timolol in preserving visual function: results from the Low-Pressure Glaucoma Treatment Study. Am J Ophthalmol 151: 671-681 Doi 10.1016/j.ajo.2010.09.026

123 Kuang TM, Zhang C, Zangwill LM, Weinreb RN, Medeiros FA (2015) Estimating Lead Time Gained by Optical Coherence Tomography in Detecting Glaucoma before Development of Visual Field Defects. Ophthalmology 122: 2002-2009 Doi 10.1016/j.ophtha.2015.06.015

124 Kurtin PS, Davies AR, Meyer KB, DeGiacomo JM, Kantz ME (1992) Patient-based health status measures in outpatient dialysis. Early experiences in developing an outcomes assessment program. Med Care 30: MS136-149

125 Kyari F, Abdull MM, Bastawrous A, Gilbert CE, Faal H (2013) Epidemiology of glaucoma in sub-saharan Africa: prevalence, incidence and risk factors. Middle East Afr J Ophthalmol 20: 111-125 Doi 10.4103/0974-9233.110605

126 Lampl Y, Lorberboym M, Blankenberg FG, Sadeh M, Gilad R (2006) Annexin V SPECT imaging of phosphatidylserine expression in patients with dementia. Neurology 66: 1253-1254 Doi 10.1212/01.wnl.0000208436.75615.8c

127 Lee DW, Kim JM, Park KH, Choi CY, Cho JG (2010) Effect of media opacity on retinal nerve fiber layer thickness measurements by optical coherence tomography. J Ophthalmic Vis Res 5: 151-157

128 Lee KM, Kim T-W, Weinreb RN, Lee EJ, Girard MJA, Mari JM (2014) Anterior lamina cribrosa insertion in primary open-angle glaucoma patients and healthy subjects. PLoS One 9: e114935 Doi 10.1371/journal.pone.0114935

129 Leeprechanon N, Giangiacomo A, Fontana H, Hoffman D, Caprioli J (2007) Frequency-doubling perimetry: comparison with standard automated perimetry to detect glaucoma. Am J Ophthalmol 143: 263-271 Doi 10.1016/j.ajo.2006.10.033

130 Lempert P, Cooper KH, Culver JF, Tredici TJ (1967) The effect of exercise on intraocular pressure. Am J Ophthalmol 63: 1673-1676

131 Li L, Bian A, Cheng G, Zhou Q (2016) Posterior displacement of the lamina cribrosa in normal-tension and high-tension glaucoma. Acta Ophthalmol 94: e492-500 Doi 10.1111/aos.13012

132 Liang J, Williams DR, Miller DT (1997) Supernormal vision and high-resolution retinal imaging through adaptive optics. J Opt Soc Am A Opt Image Sci Vis 14: 2884-2892

133 Lilja H, Ulmert D, Vickers AJ (2008) Prostate-specific antigen and prostate cancer: prediction, detection and monitoring. Nat Rev Cancer 8: 268-278 Doi 10.1038/nrc2351

134 Lima VC, Prata TS, De Moraes CG, Kim J, Seiple W, Rosen RB, Liebmann JM, Ritch R (2010) A comparison between microperimetry and standard achromatic perimetry of the central visual field in eyes with glaucomatous paracentral visual-field defects. Br J Ophthalmol 94: 64-67 Doi 10.1136/bjo.2009.159772 
135 Lin C, Mak H, Yu M, Leung CK-S (2017) Trend-Based Progression Analysis for Examination of the Topography of Rates of Retinal Nerve Fiber Layer Thinning in Glaucoma. JAMA Ophthalmol 135: 189-195 Doi 10.1001/jamaophthalmol.2016.5111

136 Liu L, Jia Y, Takusagawa HL, Pechauer AD, Edmunds B, Lombardi L, Davis E, Morrison JC, Huang D (2015) Optical Coherence Tomography Angiography of the Peripapillary Retina in Glaucoma. JAMA Ophthalmol 133: 1045-1052 Doi 10.1001/jamaophthalmol.2015.2225

137 Liu S, Lam S, Weinreb RN, Ye C, Cheung CY, Lai G, Lam DS, Leung CK (2011) Comparison of standard automated perimetry, frequency-doubling technology perimetry, and short-wavelength automated perimetry for detection of glaucoma. Invest Ophthalmol Vis Sci 52: 7325-7331 Doi 10.1167/iovs.11-7795

138 Liu Y, Allingham RR (2017) Major review: Molecular genetics of primary openangle glaucoma. Exp Eye Res 160: 62-84 Doi 10.1016/j.exer.2017.05.002

139 Lotery A (2015) New ideas for glaucoma. Eye 29: 1241 Doi 10.1038/eye.2015.153

140 Lundmark PO, Trope GE, Flanagan JG (2003) The effect of simulated obstructive apnoea on intraocular pressure and pulsatile ocular blood flow in healthy young adults. Br J Ophthalmol 87: 1363-1369

141 Lutjen-Drecoll E, May CA, Polansky JR, Johnson DH, Bloemendal H, Nguyen TD (1998) Localization of the stress proteins alpha B-crystallin and trabecular meshwork inducible glucocorticoid response protein in normal and glaucomatous trabecular meshwork. Invest Ophthalmol Vis Sci 39: 517-525

142 Macgregor S, Hewitt AW, Hysi PG, Ruddle JB, Medland SE, Henders AK, Gordon SD, Andrew T, McEvoy B, Sanfilippo PGet al (2010) Genome-wide association identifies ATOH7 as a major gene determining human optic disc size. Hum Mol Genet 19: 2716-2724 Doi 10.1093/hmg/ddq144

143 Maddess T, Hemmi JM, James AC (1998) Evidence for spatial aliasing effects in the Y-like cells of the magnocellular visual pathway. Vision Res 38: 1843-1859

144 Mandava S, Zulauf M, Zeyen T, Caprioli J (1993) An evaluation of clusters in the glaucomatous visual field. Am J Ophthalmol 116: 684-691

145 Mansouri K, Nuyen B, N Weinreb R (2013) Improved visualization of deep ocular structures in glaucoma using high penetration optical coherence tomography. Expert Rev Med Devices 10: 621-628 Doi 10.1586/17434440.2013.827505

146 Mansouri K, Shaarawy T (2011) Continuous intraocular pressure monitoring with a wireless ocular telemetry sensor: initial clinical experience in patients with open angle glaucoma. Br J Ophthalmol 95: 627-629 Doi 10.1136/bjo.2010.192922

147 Maruyama H, Morino H, Ito H, Izumi Y, Kato H, Watanabe Y, Kinoshita Y, Kamada M, Nodera H, Suzuki Het al (2010) Mutations of optineurin in amyotrophic lateral sclerosis. Nature 465: 223-226 Doi 10.1038/nature08971

148 McDaniel DR, Tribbey CL, Tobias GS (1983) Effects of moderate exercise on intraocular pressure. Am J Optom Physiol Opt 60: 154-157

149 Medeiros FA, Alencar LM, Zangwill LM, Bowd C, Sample PA, Weinreb RN (2009) Prediction of functional loss in glaucoma from progressive optic disc damage. Arch Ophthalmol 127: 1250-1256 Doi 10.1001/archophthalmol.2009.276

150 Medeiros FA, Lisboa R, Weinreb RN, Liebmann JM, Girkin C, Zangwill LM (2013) Retinal ganglion cell count estimates associated with early development of visual field defects in glaucoma. Ophthalmology 120: 736-744 Doi 10.1016/j.ophtha.2012.09.039

151 Medeiros FA, Lisboa R, Zangwill LM, Liebmann JM, Girkin CA, Bowd C, Weinreb RN (2014) Evaluation of progressive neuroretinal rim loss as a surrogate end point for 
development of visual field loss in glaucoma. Ophthalmology 121: 100-109 Doi 10.1016/j.ophtha.2013.06.026

152 Medeiros FA, Weinreb RN, Zangwill LM, Alencar LM, Sample PA, Vasile C, Bowd C (2008) Long-term intraocular pressure fluctuations and risk of conversion from ocular hypertension to glaucoma. Ophthalmology 115: 934-940 Doi 10.1016/j.ophtha.2007.08.012

153 Meira-Freitas D, Lisboa R, Tatham A, Zangwill LM, Weinreb RN, Girkin CA, Liebmann JM, Medeiros FA (2013) Predicting progression in glaucoma suspects with longitudinal estimates of retinal ganglion cell counts. Invest Ophthalmol Vis Sci 54: 4174-4183 Doi 10.1167/iovs.12-11301

154 Miki A, Medeiros FA, Weinreb RN, Jain S, He F, Sharpsten L, Khachatryan N, Hammel N, Liebmann JM, Girkin CAet al (2014) Rates of retinal nerve fiber layer thinning in glaucoma suspect eyes. Ophthalmology 121: 1350-1358 Doi 10.1016/j.ophtha.2014.01.017

155 Morton S, Hesson L, Peggie M, Cohen P (2008) Enhanced binding of TBK1 by an optineurin mutant that causes a familial form of primary open angle glaucoma. FEBS Lett 582: 997-1002 Doi 10.1016/j.febslet.2008.02.047

156 Moses RA, Carniglia PE, Grodzki WJ, Moses J (1984) Proptosis and increase of intraocular pressure in voluntary lid fissure widening. Invest Ophthalmol Vis Sci 25: 989-992

157 Musch DC, Gillespie BW, Niziol LM, Lichter PR, Varma R, CIGTS Study Group (2011) Intraocular pressure control and long-term visual field loss in the Collaborative Initial Glaucoma Treatment Study. Ophthalmology 118: 1766-1773 Doi 10.1016/j.ophtha.2011.01.047

158 Naghizadeh F, Hollo G (2014) Detection of early glaucomatous progression with octopus cluster trend analysis. J Glaucoma 23: 269-275 Doi 10.1097/IJG.0b013e3182741c69

159 Nakano M, Ikeda Y, Taniguchi T, Yagi T, Fuwa M, Omi N, Tokuda Y, Tanaka M, Yoshii K, Kageyama Met al (2009) Three susceptible loci associated with primary open-angle glaucoma identified by genome-wide association study in a Japanese population. Proc Natl Acad Sci U S A 106: 12838-12842 Doi 10.1073/pnas.0906397106

160 Normando EM, Davis BM, De Groef L, Nizari S, Turner LA, Ravindran N, Pahlitzsch M, Brenton J, Malaguarnera G, Guo Let al (2016) The retina as an early biomarker of neurodegeneration in a rotenone-induced model of Parkinson's disease: evidence for a neuroprotective effect of rosiglitazone in the eye and brain. Acta Neuropathol Commun 4: 86 Doi 10.1186/s40478-016-0346-z

161 Nouri-Mahdavi K, Brigatti L, Weitzman M, Caprioli J (1997) Comparison of methods to detect visual field progression in glaucoma. Ophthalmology 104: 1228-1236

162 O'Leary N, Chauhan BC, Artes PH (2012) Visual field progression in glaucoma: estimating the overall significance of deterioration with permutation analyses of pointwise linear regression (PoPLR). Invest Ophthalmol Vis Sci 53: 6776-6784 Doi 10.1167/iovs.12-10049

163 Odberg T, Jakobsen JE, Hultgren SJ, Halseide R (2001) The impact of glaucoma on the quality of life of patients in Norway. II. Patient response correlated to objective data. Acta Ophthalmol Scand 79: 121-124

164 Omodaka K, Takahashi S, Matsumoto A, Maekawa S, Kikawa T, Himori N, Takahashi H, Maruyama K, Kunikata H, Akiba Met al (2016) Clinical Factors Associated with Lamina Cribrosa Thickness in Patients with Glaucoma, as Measured 
with Swept Source Optical Coherence Tomography. PLoS One 11: e0153707 Doi 10.1371/journal.pone.0153707

165 Ophir A (2010) First-visit diagnosis of preperimetric glaucoma. Open Ophthalmol J 4: 22-27 Doi 10.2174/1874364101004010022

166 Organisation WH (1993) Study protocol for the World Health Organization project to develop a Quality of Life assessment instrument (WHOQOL). Qual Life Res 2: 153159

167 Orta AÖF, Öztürker ZK, Erkul SÖ, Bayraktar Ş, Yilmaz OF (2015) The correlation between glaucomatous visual field loss and vision-related quality of life. J Glaucoma 24: e121-127 Doi 10.1097/IJG.0000000000000225

168 Palmer JJ, Chinanayi F, Gilbert A, Pillay D, Fox S, Jaggernath J, Naidoo K, Graham R, Patel D, Blanchet K (2014) Trends and implications for achieving VISION 2020 human resources for eye health targets in 16 countries of sub-Saharan Africa by the year 2020. Hum Resour Health 12: 45 Doi 10.1186/1478-4491-12-45

169 Park SC, Brumm J, Furlanetto RL, Netto C, Liu Y, Tello C, Liebmann JM, Ritch R (2015) Lamina cribrosa depth in different stages of glaucoma. Invest Ophthalmol Vis Sci 56: 2059-2064 Doi 10.1167/iovs.14-15540

170 Park SC, Kung Y, Su D, Simonson JL, Furlanetto RL, Liebmann JM, Ritch R (2013) Parafoveal scotoma progression in glaucoma: humphrey $10-2$ versus $24-2$ visual field analysis. Ophthalmology 120: 1546-1550 Doi 10.1016/j.ophtha.2013.01.045

171 Partin AW, Hanks GE, Klein EA, Moul JW, Nelson WG, Scher HI (2002) Prostatespecific antigen as a marker of disease activity in prostate cancer. Oncology (Williston Park) 16: 1024-1038, 1042; discussion 1042, 1047-1028, 1051

172 Pierre-Filho Pde T, Gomes PR, Pierre ET, Pierre LM (2010) Learning effect in visual field testing of healthy subjects using Humphrey Matrix frequency doubling technology perimetry. Eye (Lond) 24: 851-856 Doi 10.1038/eye.2009.210

173 Pierre-Filho Pde T, Schimiti RB, de Vasconcellos JP, Costa VP (2006) Sensitivity and specificity of frequency-doubling technology, tendency-oriented perimetry, SITA Standard and SITA Fast perimetry in perimetrically inexperienced individuals. Acta Ophthalmol Scand 84: 345-350 Doi 10.1111/j.1600-0420.2006.00639.x

174 Pourjavan S, Boelle PY, Detry-Morel M, De Potter P (2007) Physiological diurnal variability and characteristics of the ocular pulse amplitude (OPA) with the dynamic contour tonometer (DCT-Pascal). Int Ophthalmol 27: 357-360 Doi 10.1007/s10792007-9161-7

175 Power M, Harper A, Bullinger M (1999) The World Health Organization WHOQOL100: tests of the universality of Quality of Life in 15 different cultural groups worldwide. Health Psychol 18: 495-505

176 *Prentice RL (1989) Surrogate endpoints in clinical trials: definition and operational criteria. Stat Med 8: 431-440

* This paper defines surrogate markers and proposes criteria that should be met prior to one being used in a clinical trial, as a substitute for a true clinical endpoint.

177 Pulst SM, Nechiporuk A, Nechiporuk T, Gispert S, Chen XN, Lopes-Cendes I, Pearlman S, Starkman S, Orozco-Diaz G, Lunkes Aet al (1996) Moderate expansion of a normally biallelic trinucleotide repeat in spinocerebellar ataxia type 2. Nat Genet 14: 269-276 Doi 10.1038/ng1196-269

178 Punjabi OS, Ho HK, Kniestedt C, Bostrom AG, Stamper RL, Lin SC (2006) Intraocular pressure and ocular pulse amplitude comparisons in different types of glaucoma using dynamic contour tonometry. Curr Eye Res 31: 851-862 Doi $10.1080 / 02713680600899887$ 
179 Qu J, Wang D, Grosskreutz CL (2010) Mechanisms of retinal ganglion cell injury and defense in glaucoma. Exp Eye Res 91: 48-53 Doi 10.1016/j.exer.2010.04.002

180 Quaranta L, Riva I, Gerardi C, Oddone F, Floriano I, Konstas AG (2016) Quality of Life in Glaucoma: A Review of the Literature. Adv Ther 33: 959-981 Doi 10.1007/s12325-016-0333-6

181 Quigley HA, Addicks EM, Green WR (1982) Optic nerve damage in human glaucoma. III. Quantitative correlation of nerve fiber loss and visual field defect in glaucoma, ischemic neuropathy, papilledema, and toxic neuropathy. Arch Ophthalmol 100: $135-146$

182 Quigley HA, Dunkelberger GR, Green WR (1989) Retinal ganglion cell atrophy correlated with automated perimetry in human eyes with glaucoma. Am J Ophthalmol 107: 453-464

183 Quigley HA, Green WR (1979) The histology of human glaucoma cupping and optic nerve damage: clinicopathologic correlation in 21 eyes. Ophthalmology 86: 18031830

184 Quigley HA, Guy J, Anderson DR (1979) Blockade of rapid axonal transport. Effect of intraocular pressure elevation in primate optic nerve. Arch Ophthalmol 97: 525531

185 Quigley HA, Nickells RW, Kerrigan LA, Pease ME, Thibault DJ, Zack DJ (1995) Retinal ganglion cell death in experimental glaucoma and after axotomy occurs by apoptosis. Invest Ophthalmol Vis Sci 36: 774-786

186 Qureshi IA (1995) Effects of mild, moderate and severe exercise on intraocular pressure of sedentary subjects. Ann Hum Biol 22: 545-553

187 Rafuse PE, Mills DW, Hooper PL, Chang TS, Wolf R (1994) Effects of Valsalva's manoeuvre on intraocular pressure. Can J Ophthalmol 29: 73-76

188 Ramdas WD, van Koolwijk LM, Ikram MK, Jansonius NM, de Jong PT, Bergen AA, Isaacs A, Amin N, Aulchenko YS, Wolfs RCet al (2010) A genome-wide association study of optic disc parameters. PLoS Genet 6: e1000978 Doi 10.1371/journal.pgen.1000978

189 Rao HL, Begum VU, Khadka D, Mandal AK, Senthil S, Garudadri CS (2015) Comparing glaucoma progression on 24-2 and 10-2 visual field examinations. PLoS One 10: e0127233 Doi 10.1371/journal.pone.0127233

190 Ratra V, Ratra D, Gupta M, Vaitheeswaran K (2012) Comparison between Humphrey Field Analyzer and Micro Perimeter 1 in normal and glaucoma subjects. Oman J Ophthalmol 5: 97-102 Doi 10.4103/0974-620X.99372

191 Realini T, Zangwill LM, Flanagan JG, Garway-Heath D, Patella VM, Johnson CA, Artes PH, Gaddie IB, Fingeret M (2015) Normative Databases for Imaging Instrumentation. J Glaucoma 24: 480-483 Doi 10.1097/IJG.0000000000000152

192 Rezaie T, Child A, Hitchings R, Brice G, Miller L, Coca-Prados M, Héon E, Krupin T, Ritch R, Kreutzer Det al (2002) Adult-onset primary open-angle glaucoma caused by mutations in optineurin. Science 295: 1077-1079 Doi 10.1126/science.1066901

193 Rossetti L, Digiuni M, Rosso A, Riva R, Barbaro G, Smolek MK, Orzalesi N, De Cilla S, Autelitano A, Fogagnolo P (2015) Compass: clinical evaluation of a new instrument for the diagnosis of glaucoma. PLoS One 10: e0122157 Doi 10.1371/journal.pone. 0122157

194 Schiefer U, Papageorgiou E, Sample PA, Pascual JP, Selig B, Krapp E, Paetzold J (2010) Spatial pattern of glaucomatous visual field loss obtained with regionally condensed stimulus arrangements. Invest Ophthalmol Vis Sci 51: 5685-5689 Doi 10.1167/iovs.09-5067 
195 Schlotzer-Schrehardt U, Pasutto F, Sommer P, Hornstra I, Kruse FE, Naumann GO, Reis A, Zenkel M (2008) Genotype-correlated expression of lysyl oxidase-like 1 in ocular tissues of patients with pseudoexfoliation syndrome/glaucoma and normal patients. Am J Pathol 173: 1724-1735 Doi 10.2353/ajpath.2008.080535

196 Schuman JS (2008) Spectral domain optical coherence tomography for glaucoma (an AOS thesis). Trans Am Ophthalmol Soc 106: 426-458

197 Schwartz M (2007) Modulating the immune system: a vaccine for glaucoma? Can J Ophthalmol 42: 439-441 Doi 10.3129/can j ophthalmol.i07-050

198 Sehi M, Flanagan JG, Zeng L, Cook RJ, Trope GE (2005) Relative change in diurnal mean ocular perfusion pressure: a risk factor for the diagnosis of primary open-angle glaucoma. Invest Ophthalmol Vis Sci 46: 561-567 Doi 10.1167/iovs.04-1033

199 Senatorov V, Malyukova I, Fariss R, Wawrousek EF, Swaminathan S, Sharan SK, Tomarev $S$ (2006) Expression of mutated mouse myocilin induces open-angle glaucoma in transgenic mice. J Neurosci 26: 11903-11914 Doi 10.1523/JNEUROSCI.3020-06.2006

200 Shah S, Chatterjee A, Mathai M, Kelly SP, Kwartz J, Henson D, McLeod D (1999) Relationship between corneal thickness and measured intraocular pressure in a general ophthalmology clinic. Ophthalmology 106: 2154-2160 Doi 10.1016/S01616420(99)90498-0

201 Shimizu S, Lichter PR, Johnson AT, Zhou Z, Higashi M, Gottfredsdottir M, Othman M, Moroi SE, Rozsa FW, Schertzer RMet al (2000) Age-dependent prevalence of mutations at the GLC1A locus in primary open-angle glaucoma. Am J Ophthalmol 130: $165-177$

202 Sigal IA, Wang B, Strouthidis NG, Akagi T, Girard MJ (2014) Recent advances in OCT imaging of the lamina cribrosa. Br J Ophthalmol 98 Suppl 2: ii34-39 Doi 10.1136/bjophthalmol-2013-304751

203 Skevington SM, Lotfy M, O'Connell KA, Group W (2004) The World Health Organization's WHOQOL-BREF quality of life assessment: psychometric properties and results of the international field trial. A report from the WHOQOL group. Qual Life Res 13: 299-310 Doi 10.1023/B:QURE.0000018486.91360.00

204 Song YJ, Kim YK, Jeoung JW, Park KH (2016) Assessment of Open-Angle Glaucoma Peripapillary and Macular Choroidal Thickness Using Swept-Source Optical Coherence Tomography (SS-OCT). PLoS One 11: e0157333 Doi 10.1371/journal.pone.0157333

205 Song YK, Lee C-K, Kim J, Hong S, Kim CY, Seong GJ (2014) Instability of 24-hour intraocular pressure fluctuation in healthy young subjects: a prospective, crosssectional study. BMC Ophthalmol 14: 127 Doi 10.1186/1471-2415-14-127

206 Souzeau E, Glading J, Keane M, Ridge B, Zhou T, Burdon KP, Craig JE (2014) Predictive genetic testing experience for myocilin primary open-angle glaucoma using the Australian and New Zealand Registry of Advanced Glaucoma. Genet Med 16: 558-563 Doi 10.1038/gim.2013.196

207 Souzeau E, Tram KH, Witney M, Ruddle JB, Graham SL, Healey PR, Goldberg I, Mackey DA, Hewitt AW, Burdon KPet al (2017) Myocilin Predictive Genetic Testing for Primary Open-Angle Glaucoma Leads to Early Identification of At-Risk Individuals. Ophthalmology 124: 303-309 Doi 10.1016/j.ophtha.2016.11.011

208 Spry PG, Johnson CA, McKendrick AM, Turpin A (2001) Variability components of standard automated perimetry and frequency-doubling technology perimetry. Invest Ophthalmol Vis Sci 42: 1404-1410

209 Sullivan-Mee M, Gerhardt G, Halverson KD, Qualls C (2009) Repeatability and reproducibility for intraocular pressure measurement by dynamic contour, ocular 
response analyzer, and goldmann applanation tonometry. J Glaucoma 18: 666-673 Doi 10.1097/IJG.0b013e31819c487d

210 Tahir HJ, Murray IJ, Parry NR, Aslam TM (2014) Optimisation and assessment of three modern touch screen tablet computers for clinical vision testing. PLoS One 9: e95074 Doi 10.1371/journal.pone.0095074

211 Takayama K, Hangai M, Kimura Y, Morooka S, Nukada M, Akagi T, Ikeda HO, Matsumoto A, Yoshimura N (2013) Three-dimensional imaging of lamina cribrosa defects in glaucoma using swept-source optical coherence tomography. Invest Ophthalmol Vis Sci 54: 4798-4807 Doi 10.1167/iovs.13-11677

212 Tan BB, Natividad M, Chua K-C, Yip LW (2012) Comparison of retinal nerve fiber layer measurement between 2 spectral domain OCT instruments. J Glaucoma 21: 266273 Doi 10.1097/IJG.0b013e3182071cdd

213 Tarkkanen A, Leikola J (1967) Postural variations of the intraocular pressure as measured with the Mackay-Marg tonometer. Acta Ophthalmol (Copenh) 45: 569-575

214 Teitelbaum BA, Haefs R, Connor D (2001) Interobserver variability in the estimation of the cup/disk ratio among observers of differing educational background. Optometry 72: $729-732$

215 Tezel G, Yang J, Wax MB (2004) Heat shock proteins, immunity and glaucoma. Brain Res Bull 62: 473-480 Doi 10.1016/S0361-9230(03)00074-1

216 Tham Y-C, Li X, Wong TY, Quigley HA, Aung T, Cheng C-Y (2014) Global prevalence of glaucoma and projections of glaucoma burden through 2040: a systematic review and meta-analysis. Ophthalmology 121: 2081-2090 Doi 10.1016/j.ophtha.2014.05.013

217 Thanos S, Bohm MR, Meyer zu Horste M, Prokosch-Willing V, Hennig M, Bauer D, Heiligenhaus A (2014) Role of crystallins in ocular neuroprotection and axonal regeneration. Prog Retin Eye Res 42: 145-161 Doi 10.1016/j.preteyeres.2014.06.004

218 Thimister PWL, Hofstra L, Liem IH, Boersma HH, Kemerink G, Reutelingsperger CPM, Heidendal GAK (2003) In vivo detection of cell death in the area at risk in acute myocardial infarction. J Nucl Med 44: 391-396

219 Thorleifsson G, Magnusson KP, Sulem P, Walters GB, Gudbjartsson DF, Stefansson H, Jonsson T, Jonasdottir A, Jonasdottir A, Stefansdottir Get al (2007) Common sequence variants in the LOXL1 gene confer susceptibility to exfoliation glaucoma. Science 317: 1397-1400 Doi 10.1126/science.1146554

220 Tomita G (2000) The optic nerve head in normal-tension glaucoma. Curr Opin Ophthalmol 11: 116-120

221 Traynis I, De Moraes CG, Raza AS, Liebmann JM, Ritch R, Hood DC (2014) Prevalence and nature of early glaucomatous defects in the central 10 degrees of the visual field. JAMA Ophthalmol 132: 291-297 Doi 10.1001/jamaophthalmol.2013.7656

222 Trikha S, Saffari E, Nongpiur M, Baskaran M, Ho H, Li Z, Tan PY, Allen J, Khor CC, Perera SAet al (2015) A Genetic Variant in TGFBR3-CDC7 Is Associated with Visual Field Progression in Primary Open-Angle Glaucoma Patients from Singapore. Ophthalmology 122: 2416-2422 Doi 10.1016/j.ophtha.2015.08.016

223 Tun TA, Thakku SG, Png O, Baskaran M, Htoon HM, Sharma S, Nongpiur ME, Cheng CY, Aung T, Strouthidis NGet al (2016) Shape Changes of the Anterior Lamina Cribrosa in Normal, Ocular Hypertensive, and Glaucomatous Eyes Following Acute Intraocular Pressure Elevation. Invest Ophthalmol Vis Sci 57: 4869-4877 Doi 10.1167/iovs.16-19753

224 Turner DC, Samuels BC, Huisingh C, Girkin CA, Downs JC (2017) The Magnitude and Time Course of IOP Change in Response to Body Position Change in Nonhuman 
Primates Measured Using Continuous IOP Telemetry. Invest Ophthalmol Vis Sci 58: 6232-6240 Doi 10.1167/iovs.17-22858

225 van Koolwijk LM, Ramdas WD, Ikram MK, Jansonius NM, Pasutto F, Hysi PG, Macgregor S, Janssen SF, Hewitt AW, Viswanathan ACet al (2012) Common genetic determinants of intraocular pressure and primary open-angle glaucoma. PLoS Genet 8: e1002611 Doi 10.1371/journal.pgen.1002611

226 Vesti E, Johnson CA, Chauhan BC (2003) Comparison of different methods for detecting glaucomatous visual field progression. Invest Ophthalmol Vis Sci 44: 3873 3879

227 Vieira GM, Oliveira HB, de Andrade DT, Bottaro M, Ritch R (2006) Intraocular pressure variation during weight lifting. Arch Ophthalmol 124: 1251-1254 Doi 10.1001/archopht.124.9.1251

228 Walt JG, Rendas-Baum R, Kosinski M, Patel V (2011) Psychometric evaluation of the Glaucoma Symptom Identifier. J Glaucoma 20: 148-159 Doi 10.1097/IJG.0b013e3181e07970

229 Wang W, Zhang X (2014) Choroidal thickness and primary open-angle glaucoma: a cross-sectional study and meta-analysis. Invest Ophthalmol Vis Sci 55: 6007-6014 Doi 10.1167/iovs.14-14996

230 Wang X, Harmon J, Zabrieskie N, Chen Y, Grob S, Williams B, Lee C, Kasuga D, Shaw PX, Buehler Jet al (2010) Using the Utah Population Database to assess familial risk of primary open angle glaucoma. Vision Res 50: 2391-2395 Doi 10.1016/j.visres.2010.09.018

231 Wang X, Jiang C, Ko T, Kong X, Yu X, Min W, Shi G, Sun X (2015) Correlation between optic disc perfusion and glaucomatous severity in patients with open-angle glaucoma: an optical coherence tomography angiography study. Graefes Arch Clin Exp Ophthalmol 253: 1557-1564 Doi 10.1007/s00417-015-3095-y

232 Waryah AM, Narsani AK, Sheikh SA, Shaikh H, Shahani MY (2013) The novel heterozygous Thr377Arg MYOC mutation causes severe Juvenile Open Angle Glaucoma in a large Pakistani family. Gene 528: 356-359 Doi 10.1016/j.gene.2013.07.016

233 Watson P, Stjernschantz J (1996) A six-month, randomized, double-masked study comparing latanoprost with timolol in open-angle glaucoma and ocular hypertension. The Latanoprost Study Group. Ophthalmology 103: 126-137

234 Weber J, Schultze T, Ulrich H (1989) The visual field in advanced glaucoma. Int Ophthalmol 13: 47-50

235 Weinreb RN, Kaufman PL (2011) Glaucoma research community and FDA look to the future, II: NEI/FDA Glaucoma Clinical Trial Design and Endpoints Symposium: measures of structural change and visual function. Invest Ophthalmol Vis Sci 52: 7842-7851 Doi 10.1167/iovs.11-7895

236 Weinreb RN, Shakiba S, Zangwill L (1995) Scanning laser polarimetry to measure the nerve fiber layer of normal and glaucomatous eyes. Am J Ophthalmol 119: 627636

237 White AJR, Sun H, Swanson WH, Lee BB (2002) An examination of physiological mechanisms underlying the frequency-doubling illusion. Invest Ophthalmol Vis Sci 43: 3590-3599

238 Wiggs JL, Pasquale LR (2017) Genetics of glaucoma. Hum Mol Genet 26: R21-R27 Doi $10.1093 / \mathrm{hmg} / \mathrm{ddx} 184$

239 Wild P, Farhan H, McEwan DG, Wagner S, Rogov VV, Brady NR, Richter B, Korac J, Waidmann O, Choudhary Cet al (2011) Phosphorylation of the autophagy receptor 
optineurin restricts Salmonella growth. Science 333: 228-233 Doi

10.1126/science. 1205405

240 Wilkinson CH, van der Straaten D, Craig JE, Coote MA, McCartney PJ, Stankovich J, Stone EM, Mackey DA (2003) Tonography demonstrates reduced facility of outflow of aqueous humor in myocilin mutation carriers. J Glaucoma 12: 237-242

241 Williams TA, Roberts MA, Austin MW (2010) Comparison of Clinical Interpretation Versus Progressor® Software in Visual Field Analysis in Glaucoma Follow Up. Investigative Ophthalmology \& Visual Science 51: 4001-4001

242 Wilson MR, Coleman AL, Yu F, Bing EG, Sasaki IF, Berlin K, Winters J, Lai A (1998) Functional status and well-being in patients with glaucoma as measured by the Medical Outcomes Study Short Form-36 questionnaire. Ophthalmology 105: 21122116 Doi 10.1016/S0161-6420(98)91135-6

243 Wolfs RC, Klaver CC, Ramrattan RS, van Duijn CM, Hofman A, de Jong PT (1998) Genetic risk of primary open-angle glaucoma. Population-based familial aggregation study. Arch Ophthalmol 116: 1640-1645

244 Wren PA, Musch DC, Janz NK, Niziol LM, Guire KE, Gillespie BW, CIGTS Study Group (2009) Contrasting the use of 2 vision-specific quality of life questionnaires in subjects with open-angle glaucoma. J Glaucoma 18: 403-411 Doi

10.1097/IJG.0b013e3181879e63

245 Wu Z, Lin C, Crowther M, Mak H, Yu M, Leung CK (2017) Impact of Rates of Change of Lamina Cribrosa and Optic Nerve Head Surface Depths on Visual Field Progression in Glaucoma. Invest Ophthalmol Vis Sci 58: 1825-1833 Doi 10.1167/iovs.16-20509

246 Wu Z, Xu G, Weinreb RN, Yu M, Leung CKS (2015) Optic Nerve Head Deformation in Glaucoma: A Prospective Analysis of Optic Nerve Head Surface and Lamina Cribrosa Surface Displacement. Ophthalmology 122: 1317-1329 Doi 10.1016/j.ophtha.2015.02.035

247 Yang Z, Tatham AJ, Zangwill LM, Weinreb RN, Zhang C, Medeiros FA (2015) Diagnostic ability of retinal nerve fiber layer imaging by swept-source optical coherence tomography in glaucoma. Am J Ophthalmol 159: 193-201 Doi 10.1016/j.ajo.2014.10.019

248 You JY, Park SC, Su D, Teng CC, Liebmann JM, Ritch R (2013) Focal lamina cribrosa defects associated with glaucomatous rim thinning and acquired pits. JAMA Ophthalmol 131: 314-320 Doi 10.1001/jamaophthalmol.2013.1926

249 Yu M, Lin C, Weinreb RN, Lai G, Chiu V, Leung CK-S (2016) Risk of Visual Field Progression in Glaucoma Patients with Progressive Retinal Nerve Fiber Layer Thinning: A 5-Year Prospective Study. Ophthalmology 123: 1201-1210 Doi 10.1016/j.ophtha.2016.02.017

250 Yücel YH, Zhang Q, Weinreb RN, Kaufman PL, Gupta N (2003) Effects of retinal ganglion cell loss on magno-, parvo-, koniocellular pathways in the lateral geniculate nucleus and visual cortex in glaucoma. Prog Retin Eye Res 22: 465-481

251 Zeppieri M, Demirel S, Kent K, Johnson CA (2008) Perceived spatial frequency of sinusoidal gratings. Optom Vis Sci 85: 318-329 Doi 10.1097/OPX.0b013e31816be9fd

252 Zeyen TG, Caprioli J (1993) Progression of disc and field damage in early glaucoma. Arch Ophthalmol 111: 62-65

253 Zhang C, Tatham AJ, Medeiros FA, Zangwill LM, Yang Z, Weinreb RN (2014) Assessment of choroidal thickness in healthy and glaucomatous eyes using swept source optical coherence tomography. PLoS One 9: e109683 Doi 10.1371/journal.pone.0109683 
254 Zhang X, Dastiridou A, Francis BA, Tan O, Varma R, Greenfield DS, Schuman JS, Sehi M, Chopra V, Huang Det al (2016) Baseline Fourier-Domain Optical Coherence Tomography Structural Risk Factors for Visual Field Progression in the Advanced Imaging for Glaucoma Study. Am J Ophthalmol 172: 94-103 Doi 10.1016/j.ajo.2016.09.015

255 Zhang X, Loewen N, Tan O, Greenfield DS, Schuman JS, Varma R, Huang D, Advanced Imaging for Glaucoma Study Group (2016) Predicting Development of Glaucomatous Visual Field Conversion Using Baseline Fourier-Domain Optical Coherence Tomography. Am J Ophthalmol 163: 29-37 Doi 10.1016/j.ajo.2015.11.029

256 Zhang Z, Yu M, Wang F, Dai Y, Wu Z (2016) Choroidal Thickness and Open-Angle Glaucoma: A Meta-Analysis and Systematic Review. J Glaucoma 25: e446-454 Doi 10.1097/IJG.0000000000000275

257 Zhu H, Crabb DP, Ho T, Garway-Heath DF (2015) More Accurate Modeling of Visual Field Progression in Glaucoma: ANSWERS. Invest Ophthalmol Vis Sci 56: 6077-6083 Doi 10.1167/iovs.15-16957

258 Zode GS, Bugge KE, Mohan K, Grozdanic SD, Peters JC, Koehn DR, Anderson MG, Kardon RH, Stone EM, Sheffield VC (2012) Topical ocular sodium 4-phenylbutyrate rescues glaucoma in a myocilin mouse model of primary open-angle glaucoma. Invest Ophthalmol Vis Sci 53: 1557-1565 Doi 10.1167/iovs.11-8837 
Financial Disclosures

M.F.C. is a named co-inventor on granted patent EP 2231199B1 and published patent WO 2011055121 A1 owned by UCL and related to DARC technology. The other authors declare no conflicts of interests. 